\title{
Modulation of NMDAR Subunit Expression by TRPM2 Channels Regulates Neuronal Vulnerability to Ischemic Cell Death
}

\author{
Ishraq Alim, ${ }^{1,2}$ Lucy Teves, ${ }^{1}$ Rongwen Li, ${ }^{1}$ Yasuo Mori, ${ }^{4}$ and Michael Tymianski ${ }^{1,2,3}$ \\ ${ }^{1}$ Toronto Western Hospital Research Institute, Toronto, Ontario M5T 2S8, Canada, ${ }^{2}$ Department of Physiology, University of Toronto, Toronto, Ontario \\ M5S 1A8, Canada, ${ }^{3}$ Department of Surgery (Neurosurgery), University of Toronto, Toronto, Ontario M5S 1A8, Canada, and ${ }^{4}$ Department of Synthetic \\ Chemistry and Biological Chemistry, Graduate School of Engineering, Kyoto University, Katsura Campus, Nishikyo-ku, Kyoto 615-8510, Japan
}

\begin{abstract}
Neuronal vulnerability to ischemia is dependent on the balance between prosurvival and prodeath cellular signaling. In the latter, it is increasingly appreciated that toxic $\mathrm{Ca}^{2+}$ influx can occur not only via postsynaptic glutamate receptors, but also through other cation conductances. One such conductance, the Transient receptor potential melastatin type-2 (TRPM2) channel, is a nonspecific cation channel having homology to TRPM7, a conductance reported to play a key role in anoxic neuronal death. The role of TRPM2 conductances in ischemic $\mathrm{Ca}^{2+}$ influx has been difficult to study because of the lack of specific modulators. Here we used TRPM2-null mice $\left(\right.$ TRPM $^{-l-}$ ) to study how TRPM2 may modulate neuronal vulnerability to ischemia. TRPM $2^{-l-}$ mice subjected to transient middle cerebral artery occlusion exhibited smaller infarcts when compared with wild-type animals, suggesting that the absence of TRPM2 is neuroprotective. Surprisingly, field potentials (fEPSPs) recorded during redox modulation in brain slices taken from TRPM $2^{-I-}$ mice revealed increased excitability, a phenomenon normally associated with ischemic vulnerability, whereas wild-type fEPSPs were unaffected. The upregulation in fEPSP in TRPM $2^{-1-}$ neurons was blocked selectively by a GluN2A antagonist. This increase in excitability of TRPM $^{-1-}$ fEPSPs during redox modulation depended on the upregulation and downregulation of GluN2A- and GluN2B-containing NMDARs, respectively, and on augmented prosurvival signaling via Akt and ERK pathways culminating in the inhibition of the proapoptotic factor GSK3 $\beta$. Our results suggest that TRPM2 plays a role in downregulating prosurvival signals in central neurons and that TRPM2 channels may comprise a therapeutic target for preventing ischemic damage.
\end{abstract}

\section{Introduction}

Ischemic neuronal death is caused by an activation of both glutamate and non-glutamate-dependent channels that leads to $\mathrm{Ca}^{2+}$ overload in cells (Arundine and Tymianski, 2004; Aarts and Tymianski, 2005). The traditional mechanism of glutamate-receptor-driven excitotoxicity is caused by the overactivation of $\mathrm{N}$-methyl-D-aspartate glutamate receptors (NMDARs) (Besancon et al., 2008). NMDARs are heteromers containing the obligatory GluN1 subunit along with other GluN subunits, of which GluN2A and GluN2B have been demonstrated to govern signaling pathways leading to cell survival and death, respectively. An increase in the GluN2A/ GluN2B subunit ratio promotes survival, whereas the opposite promotes prodeath mechanisms (Martel et al., 2009; Hardingham and Bading, 2010).

\footnotetext{
Received April 24, 2013; revised Aug. 30, 2013; accepted Sept. 22, 2013.

Author contributions: I.A., L.T., Y.M., and M.T. designed research; I.A., L.T., and R.L. performed research; I.A. contributed unpublished reagents/analytic tools; I.A., L.T., and R.L. analyzed data; I.A. and M.T. wrote the paper.

M.T. was supported by Canadian Institutes of Health Research Grant MOP89720 and the Canadian Stroke Network. M.T. is a Canada Research Chair (Tier 1) in Translational Stroke Research.

The authors declare no competing financial interests.

Correspondence should be addressed to Dr. Michael Tymianski, Toronto Western Hospital, WW 4-435, 399 Bathurst Street, Toronto, Ontario M5T 2S8, Canada. E-mail: mike.tymianski@uhn.ca.

DOI:10.1523/JNEUROSCI.1729-13.2013

Copyright $\odot 2013$ the authors $\quad 0270-6474 / 13 / 3317264-14 \$ 15.00 / 0$
}

Among the nonglutamatergic, $\mathrm{Ca}^{2+}$-dependent mechanisms of ischemic neuronal damage, two members of the transient receptor potential melastatin family (TRPM), TRPM7 and TRPM2, have been implicated in mediating toxic $\mathrm{Ca}^{2+}$ influx (Hara et al., 2002; Aarts et al., 2003). These nonselective cation channels are unique among ion channels in that they contain both an ion channel and an intracellular kinase domain (Nadler et al., 2001; Kraft et al., 2004). We previously showed that TRPM7 channels are important in mediating anoxic neuronal death in vitro and in vivo by a mechanism involving oxidative stress (Aarts et al., 2003; Sun et al., 2009). The analogous TRPM2 protein contains a NUDT9H (Nudix motif) domain in the $c$ terminus that is activated by adenosine diphosphate ribose (ADPR) binding directly, or by hydrogen peroxide $\left(\mathrm{H}_{2} \mathrm{O}_{2}\right)$ indirectly (Kraft et al., 2004). $\mathrm{H}_{2} \mathrm{O}_{2}$-induced activation of TRPM2 channels has been reported to cause an influx of $\mathrm{Ca}^{2+}$ in cortical and hippocampal neurons (Kaneko et al., 2006), suggesting that TRPM2, like TRPM7, may mediate its effects on neuronal death via oxidative mechanisms. Additionally, TRPM2 has been ascribed a number of physiological roles, including an involvement in inflammatory response, insulin production, and synaptic plasticity (Lange et al., 2009; Xie et al., 2011; Haraguchi et al., 2012).

Because of the lack of specific pharmacological modulators of TRPM2, most research to elucidate its role in ischemia has been limited to experiments using gene silencing or nonspecific antag- 
onists (Hara et al., 2002; Harteneck et al., 2007). However, more recently, a TRPM2-null (TRPM2 ${ }^{-1-}$ ) mouse was generated (Yamamoto et al., 2008). This provided us with an unprecedented opportunity to investigate the role of TRPM2 channels in modulating neurons' vulnerability to ischemia.

We used TRPM $2^{-1-}$ mice to determine whether TRPM2 plays a role in ischemic neuronal death in vivo and to understand the cellular mechanisms of this effect. Here we show that TRPM $2^{-/-}$is neuroprotective after in vivo ischemia-reperfusion injury and that the absence of TRPM2 promotes an increase in synaptic excitability in hippocampal CA1 neurons during redox modulation. Despite this paradoxical increase in overall synaptic excitability, a phenomenon normally associated with vulnerability to ischemia, the absence of TRPM2 causes a shift in the expression ratio of NMDAR GluN2A/GluN2B subunits. This shift upregulates known downstream prosurvival pathways. Thus, the mechanism by which the absence of TRPM2 provides neuroprotection is by selectively upregulating prosurvival signaling.

\section{Materials and Methods}

Genotyping and animals. All experiments and animal treatments were approved by the Animal Research Centre at the Toronto Western Hospital. C57B6J (wild-type [WT] and TRPM $2^{-1-}$ ) mice were used for all experiments, and TRPM2 ${ }^{-1-}$ mice were identified using PCR previously described (Yamamoto et al. 2008). In brief, tail clippings were taken from animals at time of weaning and treated with Proteinase $\mathrm{K}$ and $1 \times$ TrisEDTA buffer. DNA samples, PCR primers (described by Yamamoto et al., 2008), and HotStar TaqDNA polymerase kit (QIAGEN) were used together for PCR. After PCR, samples underwent electrophoresis in a $1 \%$ agarose gel with SYBR Green (Invitrogen) for $60 \mathrm{~min}$ using $1 \times$ TrisEDTA buffer. RT-PCR products were visualized using SYBR Green fluorescence detection on Las-3000 Imaging System (Fuji).

Stroke experiments. Transient or permanent cerebral ischemia was produced by middle cerebral artery occlusion (MCAO) as described previously (Bederson et al., 1986; Barber et al., 2004). All experiments were conducted and analyzed by individuals blinded to the animal genotype. In brief, male C57B6J mice, either WT or TRPM $2^{-1-}$ and aged $2-4$ months, were anesthetized using a $2 \%$ isoflurane-oxygen mixture. MCAO was achieved by inserting a 6-0 monofilament suture (Doccol) into the MCA via the internal carotid artery in the neck. During the first hour of occlusion, body temperature was measured using a rectal probe. Body temperature was maintained at $37.0 \pm 0.5^{\circ} \mathrm{C}$ using either heated blanket and overhead lamp (in transient ischemia) or a heating lamp above their cage (in permanent ischemia). To monitor blood flow during the occlusion, a small skin incision was made on the side ipsilateral of the stroke, and relative blood flow was monitored during the occlusion using laser Doppler flowmetry as well as visual confirmation of reduced perfusion through the skull. Occlusion was identified by a $>80 \%$ drop in blood flow. Blood flow was monitored in both transient and permanent models for $1 \mathrm{~h}$; however, in transient models, we also monitored the recovery of blood flow to ensure a return to preocclusion levels.

Animals were killed by decapitation at 48 and $24 \mathrm{~h}$ after the onset of transient $\mathrm{MCAO}$ or permanent $\mathrm{MCAO}$, respectively. Infarction volume was evaluated by removing the brain and slicing it into eight coronal sections, which were then stained using the vital stain $2 \% 2,3,5$ triphenyltetrazolium chloride (TTC). The infarct area on each slice was measured using a microcomputing imaging device (MCID), and volume was determined by integrating the infarct areas over the eight slices. To compensate for edema or loss of tissue, infarct areas from each coronal level were first mapped onto image templates derived from a mouse brain atlas and then used for area and volume calculations.

Electrophysiology. Hippocampal slices taken from 3- to 8-week-old male C57B6 mice were prepared as follows: After decapitation, the whole brain was cut into a block containing the hippocampus and placed in an ice-cold slicing solution containing the following (in $\mathrm{mm}$ ): $87 \mathrm{NaCl}, 2.5$ $\mathrm{KCl}, 25 \mathrm{NaHCO}_{3}, 0.5 \mathrm{CaCl}_{2}, 1.25 \mathrm{NaH}_{2} \mathrm{PO}_{4}, 4 \mathrm{MgCl}_{2}, 75$ sucrose, and 25 glucose (Sigma-Aldrich) for $5 \mathrm{~min}$ (Bischofberger et al., 2006). The block was cut into $500 \mu \mathrm{m}$ transverse slices with a Vibratome 1500 (Vibratome) and incubated for $1 \mathrm{~h}$ in ACSF containing the following (in mM): 125 $\mathrm{NaCl}, 2.5 \mathrm{KCl}, 25 \mathrm{NaHCO}_{3}, 2 \mathrm{CaCl}_{2}, 1.25 \mathrm{NaH}_{2} \mathrm{PO}_{4}, 1 \mathrm{MgCl}_{6} \mathrm{H}_{2} \mathrm{O}$, and 10 glucose (Sigma-Aldrich), $\mathrm{pH} 7.4$, at $32^{\circ} \mathrm{C}$. The ACSF was saturated with $95 \% \mathrm{O}_{2}-5 \% \mathrm{CO}_{2}$ gas mixture. After incubation, the slices were placed in a submerged recording chamber. Recordings were made with a glass pipette (3-4 M $\Omega$ ) containing ACSF and placed in the dendritic fields of the CA1 sector of the hippocampus. Stimulation was delivered through a bipolar electrode (FHC) placed in the Schaffer collaterals. Baseline fEPSP were recorded by delivering 100-200 uA pulses every $10 \mathrm{~s}$. Long-term potentiation (LTP) was induced by high-frequency stimulation (HFS) consisting of a $1 \mathrm{~s}$ train of $100 \mathrm{~Hz}$ pulses. Paired-pulse facilitation was induced by evoking two pulses in rapid succession with varying $20-1000 \mathrm{~ms}$ interpulse intervals. Oxidative stress was induced by bath application of $200 \mu \mathrm{M}$ hydrogen peroxide (Maalouf and Rho, 2008). To determine the effects of GluN2A and GluN2B NMDAR subunits on the recordings, $0.4 \mu \mathrm{M}$ of the GluN2A-specific antagonist PEAQX tetrasodium hydrate (also referred to as NVP-AAM007; Sigma-Aldrich) or $0.5 \mu \mathrm{M}$ of the GluN2B-specific antagonist Ro 25-6981 (Sigma-Aldrich) was added to the bath medium 10 min after addition of $\mathrm{H}_{2} \mathrm{O}_{2}$. These were selected because they were demonstrated in prior studies to inhibit specifically their target NMDAR subunits without affecting baseline fEPSP (Liu et al., 2004; Y. Liu et al., 2007). Data acquisition and analysis were performed using pClamp 10 (Molecular Devices).

Tissue cultures. Mixed hippocampal cell cultures containing neurons and glia were prepared from E18 pups from WT and TRPM2 ${ }^{-1-}$ mothers, as described previously (Olah et al., 2009). Each pup was plated individually, and tail clippings were used for PCR to detect the SRY (sex determination on chromosome Y) gene, which determines male and female sex, as described previously (M. Liu et al., 2007). Hippocampi from pups were micro-dissected into HBSS (Invitrogen), and then cells were dissociated by incubation at $37^{\circ} \mathrm{C}$ for $10 \mathrm{~min}$ in $0.05 \%$ trypsin, followed by titration. Trypsin was inactivated by HBSS and the suspension centrifuged to isolate cells. Hippocampal neurons were seeded in poly D-lysine-coated glass coverslips or in 24-well plates (for oxygen glucose deprivation [OGD] or Western blot experiments) at a density of $0.5 \times 10^{5}$ neurons per coverslip/well using Neurobasal (Invitrogen) at $37^{\circ} \mathrm{C}$. After $3 \mathrm{~d}$ in vitro, growth of non-neuronal cells was halted by a $48 \mathrm{~h}$ treatment with $10 \mu \mathrm{M}$ FDU solution ( $5 \mu \mathrm{M}$ uridine, $5 \mu \mathrm{M}(+)$-5-fluor2 '-deoxyuridine). Our prior studies have demonstrated that FDUtreated mouse cultures are comprised of $>85 \%$ neurons (Sattler et al., 1997). These primary hippocampal neuronal cultures were allowed to mature by incubation for $13 \mathrm{~d}$ with regular medium changes.

Primary glial cultures were prepared from hippocampi of E18 pups from WT and TRPM $2^{-1-}$ mothers, as described previously (Zawadzka and Kaminska, 2003). In brief, cells were dissociated from whole hippocampus by incubating in $0.05 \%$ trypsin for $10 \mathrm{~min}$ at $37^{\circ} \mathrm{C}$. Trypsin was inactivated in Dulbecco's PBS (Invitrogen). Glial cells were plated on poly D-lysine-coated $60 \times 15 \mathrm{~mm}$ cultures dishes at $1 \times 10^{6}$ cells/dish and maintained in DMEM with Glutamax (Invitrogen) containing 10\% FBS and $1 \%$ antibiotics. Primary glial cultures were allowed to mature for $15 \mathrm{~d}$ with medium changes ever 2-3 d.

Western blots. Whole hippocampal lysates and primary hippocampal neuronal and glial cultures from WT and TRPM $2^{-1-}$ animals were used for gel electrophoresis and blotting as described previously (Soriano et al., 2008). Lysis buffer with protease and phosphatase inhibitor was used to suspend cultured cells and to break down whole hippocampal tissue. Membranes were incubated at $4^{\circ} \mathrm{C}$ overnight with primary antibodies with 5\% dried milk in PBS. Primary antibodies used were as follows: anti-GluA2 and anti-GluN1 (Milipore), anti-GluN2B, anti-phospho-GluN2B, antipsd95, anti-pser473 Akt, anti-Akt, anti-pthr308 Akt, anti-ERK, anti-pERK, anti-pGSK3 $\beta$, and anti-phosphotyrosine kinase A (Cell Signaling Technology), and anti-GluA1 and anti-GluN2A (Abcam). Phosphotyrosine kinase A antibody has been shown to detect phospho-TRKB on tyrosine 515, and hippocampal neurons do not express TRKA (Friedman, 2000). HRP-based secondary antibodies were used for $2 \mathrm{~h}$ and visualized using chemiluminescent detection on a Las-3000 Imaging System (Fuji). Densitometry was conducted using Photoshop Elements (Adobe), and all bands were normalized to a loading control of $\beta$-actin (Sigma-Aldrich). 
Immunofluorescence for quantification of GluN2 subunit expression. Immunofluorescence and quantification of synaptic clusters were conducted in low-density hippocampal cultures as described previously ( $\mathrm{Li}$ et al., 2005.). In brief, mature hippocampal cell cultures were fixed in $4 \%$ paraformaldehyde and $4 \%$ sucrose in PBS for $20 \mathrm{~min}$, permeabilized with $0.1 \%$ Triton X-100 for $10 \mathrm{~min}$ at $4^{\circ} \mathrm{C}$, and blocked with $10 \%$ goat serum in PBS for $1 \mathrm{~h}$ at room temperature. Cultures were double-labeled using anti-VGLUT1 (a synaptic marker, vesicular glutamate transporter; Abcam) as well as with antibodies against NMDA receptor subunits (same as ones used in Western blots). After washing, cells were incubated in fluorophore-labeled secondary antibodies (anti-species-specific IgG). Immunofluorescence was visualized on a Nikon TE-300 inverted microscope using $40 \times$ oil-immersion lens. Images were captured using NISElements (Nikon) and analyzed using Photoshop. In each culture, 2 or 3 individual neurons were randomly selected; and for each neuron, a $2 \times$ $50 \mu \mathrm{m}$ area was analyzed in 3 different dendrites, giving a total of $24-27$ dendrites per group. Fluorescence was normalized to the maximum intensity of the fluorophore channel, and background fluorescence of each dendrite was subtracted. For each section, puncta representing GluN2A/ GluN2B clusters and VGLUT clusters were individually counted. Images of GluN2 subunit and VGLUT clusters were overlapped, and each GluN2 cluster that overlapped with VGLUT cluster was used to quantify changes NMDAR GluN2 subunit synaptic colocalization.

OGD. OGD conditions previously described by Aarts et al. (2003) were used. Primary hippocampal neuronal cultures from WT and TRPM $2^{-1-}$ pups were washed 3 times using deoxygenated HBSS without glucose. Neuronal cultures were then housed in an anoxia chamber (Forma Anaerobic System, Fisher Scientific) containing a $5 \% \mathrm{CO}_{2}, 10 \% \mathrm{H}_{2}$, and $85 \% \mathrm{~N}_{2}\left(<0.2 \% \mathrm{O}_{2}\right)$ atmosphere at $37^{\circ} \mathrm{C}$ for $1 \mathrm{~h}$. After OGD, medium was washed and replaced with neurobasal medium devoid of phenol red and containing $1 \mu \mathrm{g} / \mathrm{ml}$ propidium iodide (staining), which increases its fluorescence when in contact with dead cells. Fluorescence was measured immediately after OGD (F0) and after $24 \mathrm{~h}$ incubation (F24). Cultures were then treated with $1 \mathrm{~mm}$ NMDA for 30 min to kill all remaining neurons, and maximum fluorescence was measured $\left(\mathrm{F}_{\max }\right)$. We also applied $0.05 \%$ Triton X-100 after the NMDA treatment to kill off the remaining cells and observed a $5-15 \%$ increase in propidium iodide fluorescence, consistent with a $5-15 \%$ content of non-neuronal (glial) cells (Sattler et al., 1997). Cell death was calculated using the following formula: Fraction dead $=(\mathrm{F} 24-\mathrm{F} 0) /\left(\mathrm{F}_{\max }-\mathrm{F} 0\right)$. Cultures tested in non-OGD conditions were washed with HBSS containing glucose. During OGD, cell cultures were also treated with catalase $(30-300 \mathrm{U} / \mathrm{ml}$; Sigma-Aldrich), GluN2A inhibitors $0.4 \mu \mathrm{M}$ PEAQX and $10 \mu \mathrm{M}$ TCN201 (Tocris Bioscience), and GluN2B inhibitors 0.5 $\mu \mathrm{M}$ RO25-6981 and 0.5 $\mu \mathrm{M}$ Co101244 (Tocris Bioscience). The concentrations selected were shown to selectively inhibit the respective GluN2 subunits in prior studies (Liu et al., 2004; Stanika et al., 2009; Bettini et al., 2010). All drugs were dissolved in water, except TCN201, which was dissolved in DMSO.

Statistical analysis. All statistical analyses were conducted using Graph Pad (Prism), and significance was determined using an unpaired Student's $t$ test or a one-way ANOVA with a Bonferroni correction as required. All data are presented as mean \pm SEM.

\section{Results}

The absence of TRPM2 reduces infarct volume after transient, but not permanent, cerebral ischemia

In cultured neurons, the TRPM 2 conductance is activated by reactive oxygen species and, particularly, $\mathrm{H}_{2} \mathrm{O}_{2}$ (Hara et al., 2002; Olah et al., 2009). However, published attempts to prevent oxidative stress-induced neuronal death by inhibiting TRPM2 have produced inconsistent results. In particular, TRPM2 knockdown using antisense siRNA imparted neuroprotection to cortical neurons subjected to oxidative stress with $\mathrm{H}_{2} \mathrm{O}_{2}$ (Kaneko et al., 2006). However, experiments using nonspecific TRPM2 antagonists did not protect hippocampal neurons against lethal $\mathrm{H}_{2} \mathrm{O}_{2}$ challenges (Bai and Lipski, 2010). To resolve this inconsistency and to examine the in vivo situation, we used TRPM2 ${ }^{-1-}$ mice to investigate whether the absence of TRPM2 affected vulnerability to cerebral ischemia after MCAO. First, TRPM2-null and WT animals were subjected to a transient middle cerebral artery occlusion (tMCAO) of $1 \mathrm{~h}$ duration followed by a $48 \mathrm{~h}$ reperfusion period. In tMACAO, there is a partial restoration of blood flow as was confirmed by laser Doppler flowmetry for up to $30 \mathrm{~min}$ after reperfusion (Fig. 1C). Infarct volumes were measured from each brain section after TTC staining (see Materials and Methods; Fig. $1 A$, infarct depicted in white). Both WT and TRPM $2^{-1-}$ animals sustained cerebral infarcts as assessed at $48 \mathrm{~h}$ after the $1 \mathrm{~h}$ tMCAO. However, the TRPM $2^{-/-}$animals exhibited a $36.43 \pm 16.65 \%$ reduction in infarct volumes compared with the WT controls $(p<$ $0.05 ; n=8$; Fig. $1 B$ ). Thus, the absence of TRPM2 protein imparts in mice a state of reduced vulnerability to cerebral ischemia after tMCAO.

Next, we explored whether the absence of TRPM2 had similar effects in animals subjected to permanent MCAO (pMCAO). In these experiments, the MCA was occluded permanently by leaving the occlusive intravascular suture in place (see Materials and Methods), and the infarct volumes were assessed at $24 \mathrm{~h}$. This model lacks reperfusion, as was evidenced by a lack of recovery of blood flow as measured for up to $1 \mathrm{~h}$ after the MCAO onset with a laser Doppler (Fig. $1 F$ ). By contrast with tMCAO, there were no differences in infarct volumes between WT and TRPM2 ${ }^{-1-}$ mice subjected to pMCAO (Fig. $1 D, E ; p>0.05 ; n=5$ ).

Our findings suggest that the absence of TRPM 2 imparts resistance to cerebral ischemia when it is followed by reperfusion, but not in the absence of reperfusion. This may indicate that pMCAO may produce ischemia of such severity that the potential cytoprotective benefits of TRPM2 deficiency are outweighed. However, reperfusion is known to cause an increase in ROS, including $\mathrm{H}_{2} \mathrm{O}_{2}$ (Simonson et al., 1993), and $\mathrm{H}_{2} \mathrm{O}_{2}$ has been specifically demonstrated to activate TRPM2-like currents in monocytes, hippocampal neurons, cortical neurons, and microglia (Kraft et al., 2004; Kaneko et al., 2006; Yamamoto et al., 2008; Olah et al., 2009). Thus, one possibility is that TRPM2-null mice exhibit resistance to ischemia-reperfusion because of a reduced vulnerability to $\mathrm{H}_{2} \mathrm{O}_{2}$ toxicity.

\section{TRPM2 $2^{-/-}$increases synaptic excitability during redox modulation}

An ischemic insult produces a disruption of synaptic function and an overproduction of ROS, including $\mathrm{H}_{2} \mathrm{O}_{2}$, a known modulator of TRPM2 currents (Hara et al., 2002; Kraft et al., 2004). Given the relative resistance of TRPM $2^{-1-}$ animal brains to ischemia-reperfusion, we examined whether the absence of TRPM2 alters synaptic function in response to $\mathrm{H}_{2} \mathrm{O}_{2}$ in a manner that might explain the observed reduction in ischemic vulnerability. Sublethal concentrations of $\mathrm{H}_{2} \mathrm{O}_{2}$ inhibit both normal synaptic function and plasticity, including inhibiting LTP (Colton et al., 1989; Kamsler and Segal, 2003). Thus, we examined the effects of sublethal concentrations of $\mathrm{H}_{2} \mathrm{O}_{2}$ on synaptic function in hippocampal slices taken from WT and TRPM2 $2^{-1-}$ animals. To this end, we studied fEPSPs evoked in the CA1 sector of the hippocampus by stimulating the Schaffer collaterals.

Under control conditions (superfusion with normal ACSF), there were no differences in fEPSP slopes of CA1 neurons recorded from slices taken from WT and TRPM $2^{-1-}$ animals (Fig. $2 A, B)$. These findings are consistent with recent data demonstrating that the absence of TRPM2 had no effect on baseline fEPSP in the CA1 dendritic field of hippocampal slices under control ACSF conditions (Xie et al., 2011).

Previous studies examining the effects of $\mathrm{H}_{2} \mathrm{O}_{2}$ on synaptic excitability have been conducted in Wistar rat brain slices (Kam- 

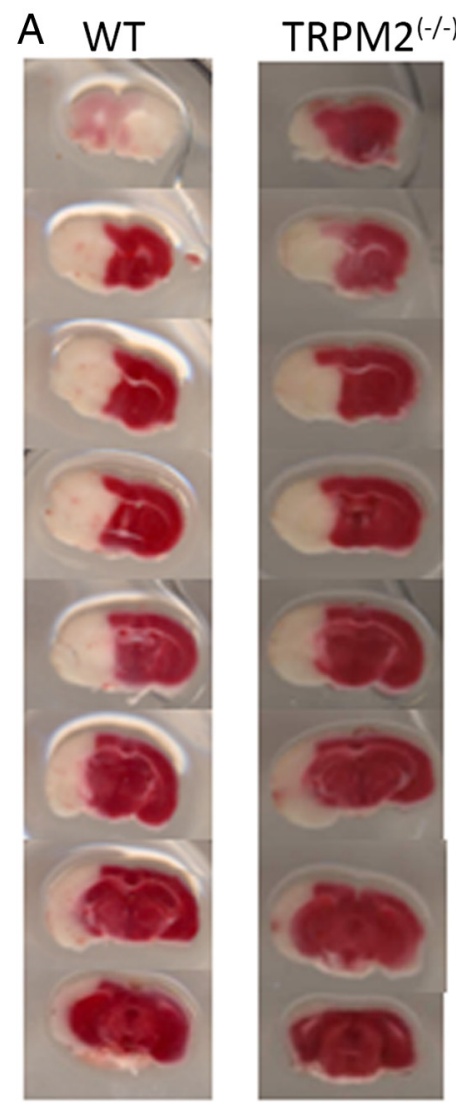

$\mathrm{B}$

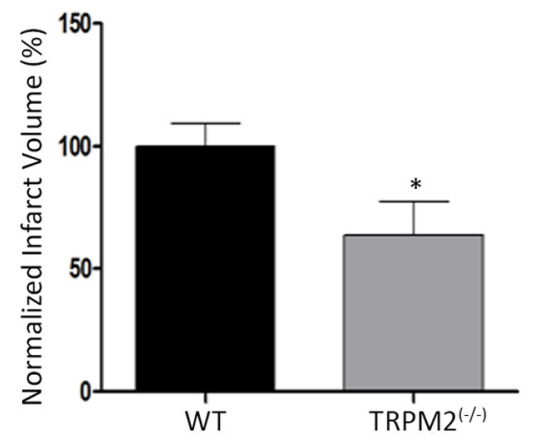

C

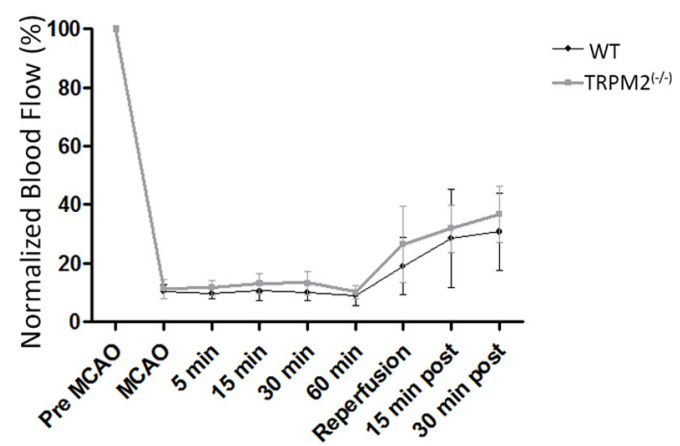

Time Point
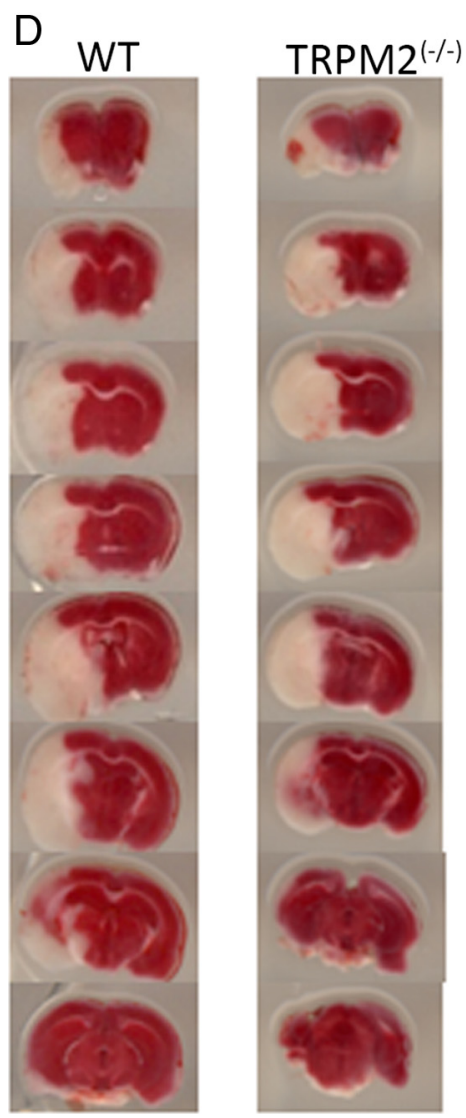

E
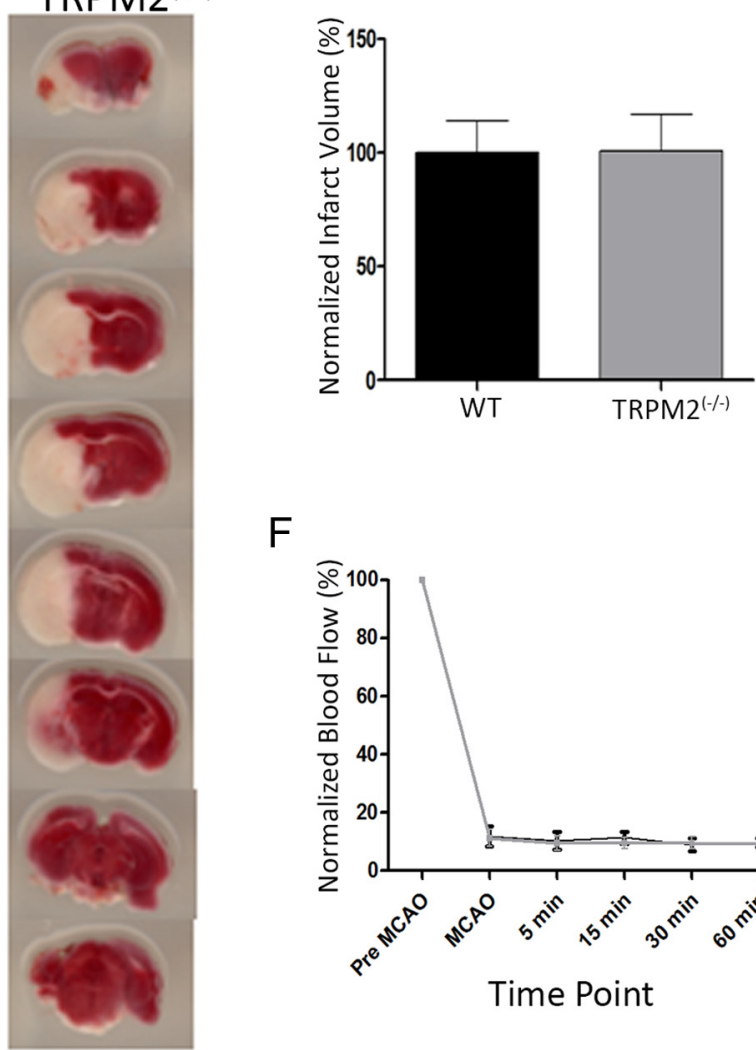

$\mathrm{F}$

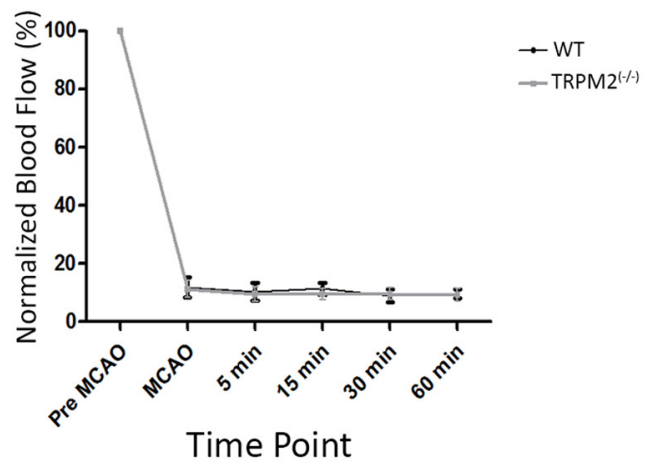

Figure 1. TRPM2 ${ }^{-1-}$ reduces infarct volume in transient MCAO, but not in permanent MCAO. MCAO was induced in both WT and TRPM2 ${ }^{-1-}$ animals. The brains were processed into coronal sections that were stained with TTC. $A, B$, Infarcts assessed at $48 \mathrm{~h}$ after a $1 \mathrm{~h} \mathrm{tMCA0}$. Left, Representative coronal sections from WT and TRPM2 ${ }^{-1-}$ mice. White areas (Figure legend continues.) 
A
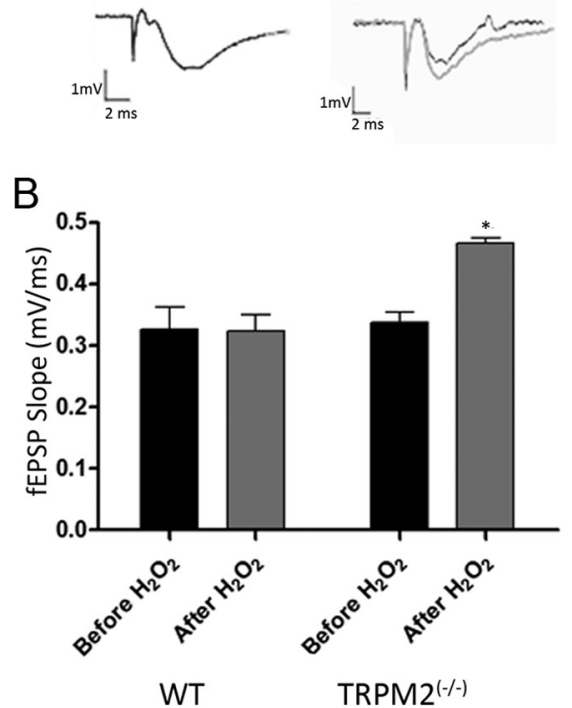

C
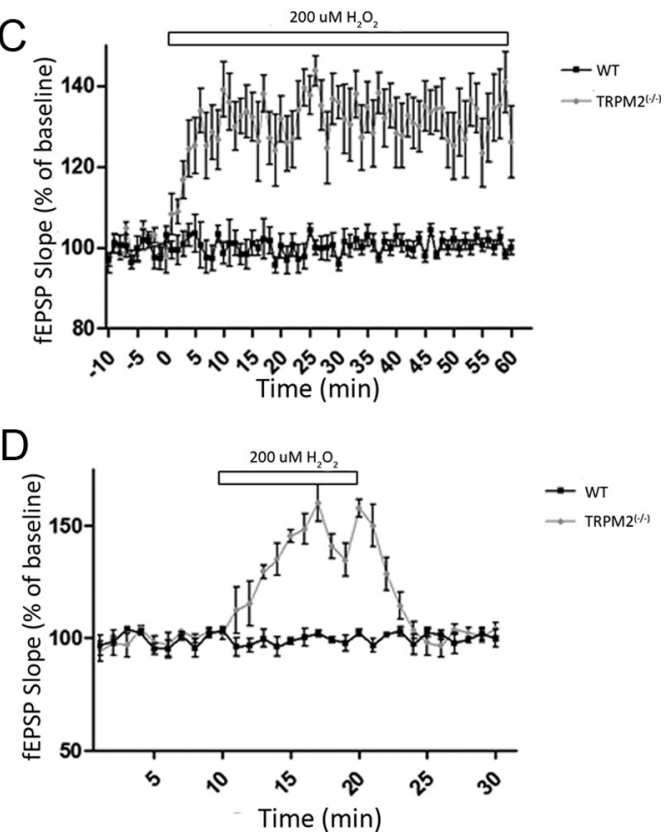

Figure 2. $\quad \mathrm{H}_{2} \mathrm{O}_{2}(200 \mu \mathrm{M})$ selectively increases the evoked baseline fEPSP slope in TRPM2 $2^{-1-}$ neurons. Field potentials (fEPSP) evoked via stimulation in the Schaffer collaterals (at $\left.100-200 \mu \mathrm{A}\right)$ were recorded in the hippocampal CA1 region in slices from TRPM2 ${ }^{-1-}$ and WT mice under control (ACSF) and oxidative (ACSF $+200 \mu \mathrm{M} \mathrm{H}_{2} \mathrm{O}_{2}$ ) conditions. $\mathrm{H}_{2} \mathrm{O}_{2}$ was administered through bath application. $\boldsymbol{A}, \boldsymbol{B}$, Both WT and TRPM2 ${ }^{-I-}$ had similar raw fEPSP slope during baseline recordings (black bar); and during $\mathrm{H}_{2} \mathrm{O}_{2}$ exposure (gray bar), TRPM2 ${ }^{-l-}$ slices showed a $49.0 \pm 3.4 \%$ increase in fEPSP slope: ${ }^{*} p<0.05$. Representative fEPSP recordings $(\boldsymbol{A})$ using gray and black to represent with and without $\mathrm{H}_{2} \mathrm{O}_{2}$, respectively, showed this effect in TRPM2 ${ }^{-/-}$. $\boldsymbol{C}, A$ longer application of $\mathrm{H}_{2} \mathrm{O}_{2}$ caused fEPSP to increase in TRPM2 ${ }^{-l-}\left(n=7\right.$; gray) for as long as it is applied (60 min), without any effect in WT $\left(n=5\right.$; black). D, The $\mathrm{H}_{2} \mathrm{O}_{2}$-induced increase in fEPSP in TRPM2 $^{-1-}$ (gray; $n=8$ ) was found to be reversible when application of $200 \mu \mathrm{M} \mathrm{H}_{2} \mathrm{O}_{2}$ (white bar) was removed, with no effect on WT (black; $n=8$ ).

sler and Segal, 2003; Maalouf and Rho, 2008). These demonstrated that bath application of $200 \mu \mathrm{M}$ of $\mathrm{H}_{2} \mathrm{O}_{2}$ had no effect on baseline fEPSP. However, LTP formation was inhibited (Vereker et al., 2001; Maalouf and Rho, 2008). Thus, we examined the effects of $\mathrm{H}_{2} \mathrm{O}_{2}$ in the TRPM2 ${ }^{-/-}$mice. Consistent with previous results, $200 \mu \mathrm{M}$ of $\mathrm{H}_{2} \mathrm{O}_{2}$ had no effect on baseline fEPSP in WT CA1 neurons. However, when applied to slices taken from TRPM2 $2^{-1-}$ animals, $\mathrm{H}_{2} \mathrm{O}_{2}$ caused a $49.0 \pm 3.4 \%$ increase in baseline fEPSP slope $(p<0.01 ; n=8$; Fig. $2 A, B)$. This increase in excitability lasted throughout the $60 \mathrm{~min}$ duration of the recordings (Fig. 2C) and was reversible in that, when $\mathrm{H}_{2} \mathrm{O}_{2}$ was removed from the bath solution, the baseline fEPSP slope of TRPM2 ${ }^{-1-}$ slices returned back to control levels (Fig. 2D). These findings were surprising in the context of the relative resilience of TRPM2 ${ }^{-I-}$ mice to cerebral ischemia. We expected this resilience to be associated with a reduced excitability in the face of potential oxidative stress rather than an increased excitability. Moreover, $\mathrm{H}_{2} \mathrm{O}_{2}$ is a known activator of TRPM2 currents (Kraft et al., 2004), so the absence of TRPM2 should reduce excitability. Our counterintuitive findings of increased excitability suggest that the absence of TRPM2 has unexpected effects on the channels that are responsible for these synaptic responses.

\section{TRPM2 $2^{-1-}$ has no effect on LTP inhibition and paired-pulse facilitation observed during redox modulation}

To further explore the mechanisms by which the absence of TRPM2 may modulate synaptic mechanisms, we evaluated LTP

\section{$\leftarrow$}

(Figure legend continued.) represent ischemic damage from infarct. Right, Comparison of infarct volumes. There was a reduction of $36.43 \pm 16.65 \%$ in infarct volumes in the TRPM2 $2^{-1-}$ animals $(n=8)$ compared with WT: ${ }^{*} p<0.05 . \boldsymbol{D}, \boldsymbol{E}$, Infarcts assessed pMCA0. There were no significant differences between infarct volumes in WT and TRPM2 ${ }^{-1-}$ animals $(n=5): p>$ 0.05. C, F, Blood flow was measured using laser Doppler, pMCAO was confirmed for $1 \mathrm{~h}$ after occlusion, and reflow was confirmed in TMCAO for up to 30 min after MCAO. and paired-pulse facilitation paradigms as measures of synaptic plasticity. LTP was induced in both WT and TRPM $2^{-1-}$ CA1 neurons in hippocampal slices by using $100 \mathrm{hz}$ HFS of the Schaffer collaterals. LTP was readily induced in slices taken from TRPM $2^{-/-}$animals, similarly to that inducible in WT slices (Fig. $3 A, B)$. To examine the impact of redox modulation on LTP induction, $200 \mu \mathrm{M} \mathrm{H}_{2} \mathrm{O}_{2}$ was applied $10 \mathrm{~min}$ before LTP induction. This had no effect on baseline fEPSPs in WT slices but inhibited LTP formation $(n=10$; Fig. $3 A)$. These findings are consistent with previous studies (Vereker et al., 2001; Maalouf and Rho, 2008).

When $\mathrm{H}_{2} \mathrm{O}_{2}$ was applied to hippocampal slices from TRPM $2^{-1-}$ animals before LTP induction, we again observed the change in the baseline fEPSP slope. When this was followed by HFS, LTP could not be induced. Rather, the fEPSP returned to the new baseline levels of heightened baseline excitability produced by $\mathrm{H}_{2} \mathrm{O}_{2}(n=10$; Fig. $3 B)$. This result suggests that either the $\mathrm{H}_{2} \mathrm{O}_{2}$-induced increase in synaptic excitability in TRPM2 ${ }^{-1-}$ is not occurring through the same mechanisms that induce LTP or that pretreating slices with $\mathrm{H}_{2} \mathrm{O}_{2}$ before LTP induction causes a ceiling effect in the excitability of TRPM2 $2^{-1-}$ CA1 neurons. However, the latter explanation is unlikely because, when $\mathrm{H}_{2} \mathrm{O}_{2}$ was removed from the bath solution after LTP induction, fEPSP slope returned to the older baseline levels seen before the $\mathrm{H}_{2} \mathrm{O}_{2}$ application (data not shown).

Our results suggest that LTP induction by HFS and LTP inhibition by $\mathrm{H}_{2} \mathrm{O}_{2}$ are unaffected by the absence of TRPM2. Thus, to further explore the source of the hyperexcitability observed in the fEPSP measurements, we evaluated whether $\mathrm{H}_{2} \mathrm{O}_{2}$ is affecting the presynapse, causing increased neurotransmitter release or whether it is affecting the postsynapse by activating more excitatory glutamate receptors. To resolve this, we used paired-pulse facilitation. Each paired-pulse sweep consisted of two pulses evoked at rapid succession with varying $(20-1000 \mathrm{~ms})$ interpulse intervals. Facilitation oc- 
A
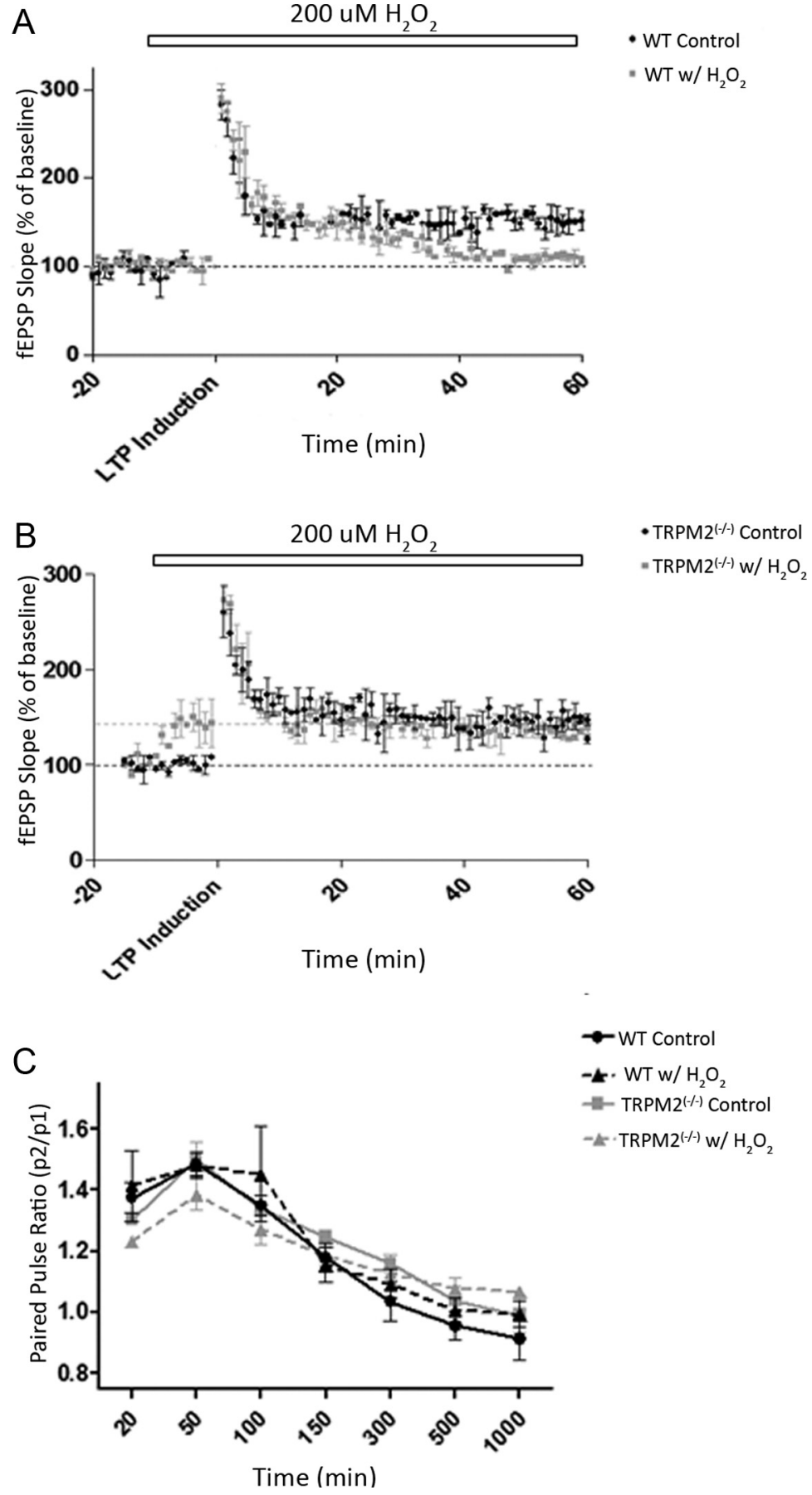

Figure 3. $\mathrm{H}_{2} \mathrm{O}_{2}(200 \mu \mathrm{M})$ inhibits LTP formation in both WT and TRPM2 ${ }^{-1-}$. Synaptic plasticity was induced by stimulating the Schaffer collaterals and measuring changes in fEPSPs in the dendrites of CA1 hippocampal neurons. $A, B$, LTP was induced by HFS, and fEPSPs were recorded both before HFS (for $20 \mathrm{~min}$ ) and after HFS (for $60 \mathrm{~min}$ ). $\mathrm{H}_{2} \mathrm{O}_{2}(200 \mu \mathrm{M}$ ) was applied at $10 \mathrm{~min}$ before HFS (white bar). Slices from WT $(n=10 ; \boldsymbol{A})$ and TRPM2 ${ }^{-1-}(n=10 ; \boldsymbol{B})$ animals were able to form LTP under control conditions (ACSF; black), and LTP formation was blocked by $200 \mu \mathrm{M} \mathrm{H} \mathrm{O}_{2}$ (gray) in both WT and TRPM2 ${ }^{-\prime-}$. Black dotted line indicates baseline fEPSPs under ACSF; gray dotted line indicates baseline of TRPM2 ${ }^{-1-}$ with $\mathrm{H}_{2} \mathrm{O}_{2}$ (only in $\boldsymbol{B}$ ). $\boldsymbol{C}$, Paired pulse facilitation was induced by giving two pulses with the same amplitude $(100-200 \mu \mathrm{A})$ at different interpulse intervals. There were no observable changes in paired pulse facilitation between slices from TRPM2 $2^{-I-}$ and WT animals under both control (ACSF) and with $200 \mu \mathrm{M} \mathrm{H}_{2} \mathrm{O}_{2}$ ( $n=$ 10 each group).

curs solely in the presynapse as a result of an increased probability of neurotransmitter release induced by $\mathrm{Ca}^{2+}$ entry evoked by the first pulse.

We found no change in the paired-pulse ratios at different interpulse intervals when comparing hippocampal slices from WT and TRPM $2^{-1-}$ mice under normal ACSF conditions $(p>$
0.05; $n=10$; Fig. 3C). Previously, it was shown that $200 \mu \mathrm{M}$ of $\mathrm{H}_{2} \mathrm{O}_{2}$ had no effect on paired-pulse ratios in the hippocampus (Colton et al., 1989). Presently, the application of $200 \mu \mathrm{M}$ of $\mathrm{H}_{2} \mathrm{O}_{2}$ to hippocampal slices from WT and TRPM $2^{-1-}$ animals resulted in no change in the paired-pulse ratios of WT and TRPM $2^{-1-}$ slices compared with control slices in $\operatorname{ACSF}(p>0.05 ; n=10$; Fig. $3 C$ ). This suggests that $\mathrm{H}_{2} \mathrm{O}_{2}$ does not function presynaptically to increase excitability in TRPM2 ${ }^{-1-}$ CA1 neurons; therefore, redox modulation is likely to be affecting evoked synaptic excitability postsynaptically.

\section{The absence of TRPM2 alters NMDAR GluN2 subunit expression}

In the postsynapse, ionotropic glutamate receptors are responsible for the EPSPs and have roles in a numerous cellular mechanisms. Under normal conditions, glutamate receptors play a role in neuronal excitability and plasticity (Bliss and Collingridge, 1993), but under ischemic conditions they often lead to cell death (Lau and Tymianski, 2010). Given that the absence of TRPM2 increases excitability but reduces ischemic vulnerability, we evaluated whether this might be explained by alterations in glutamate receptor subunit composition. Specifically, we focused on the expression of GluN2A and GluN2B subunits because, among NMDAR subunits, GluN2A and GluN2B are known to be involved in a number of cellular functions related to cell death and survival and are found in different locations in the membrane (Zhou and Baudry, 2006; Y. Liu et al., 2007; Chen et al., 2008; Terasaki et al., 2010). In mature neurons, GluN2Bcontaining NMDARs are predominantly located extrasynaptically and are involved in cell death mechanisms as well as synaptic inhibition (Y. Liu et al., 2007; Soriano et al., 2008). By contrast, GluN2Acontaining NMDARs are concentrated at synapses and are involved in cell survival mechanisms, as well as synaptic excitation (Y. Liu et al., 2007; Hardingham and Bading, 2010; Terasaki et al., 2010).

Using Western blots from whole hippocampi extracted from either WT and TRPM $2^{-1-}$ male animals, we found that, in TRPM2 ${ }^{-1-}$ animals, GluN2B expression levels were decreased by $46.21 \pm$ $3.18 \%(n=3 ; p<0.01$; Fig. $4 E)$. Concomitantly, GluN2A subunit expression was increased in the TRPM $2^{-1-}$ hippocampi by $43.30 \pm 2.33 \%(n=3 ; p<0.01$; Fig. $4 D)$ compared with WT. This change was selective for GluN2 subunits because there was no change in the expression of the AMPAR subunit proteins GluA1 and GluA2 ( $p>0.05 ; n=4$; Fig. $4 A, B)$. The expression of phospho-GluN2B was also reduced in 
A

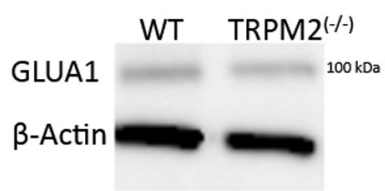

C

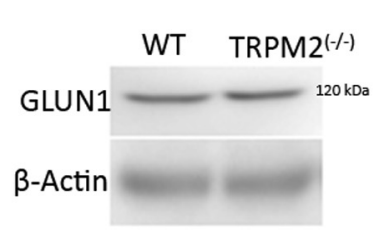

E

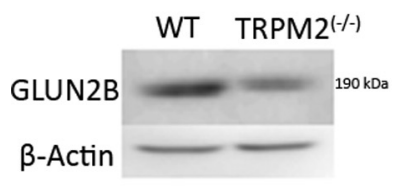

G

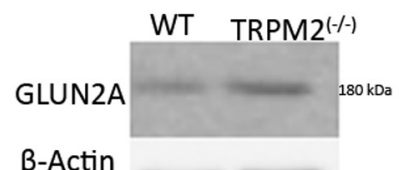

$\beta$-Actin
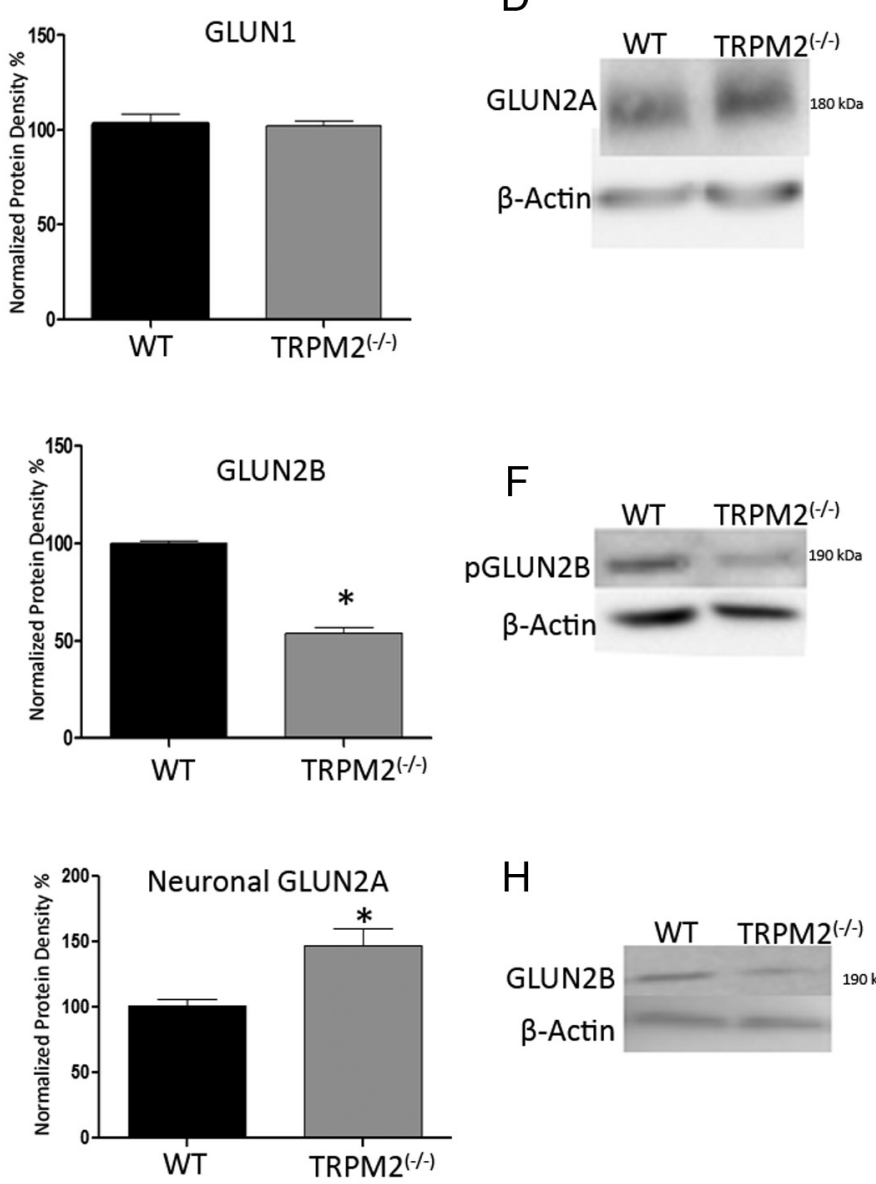
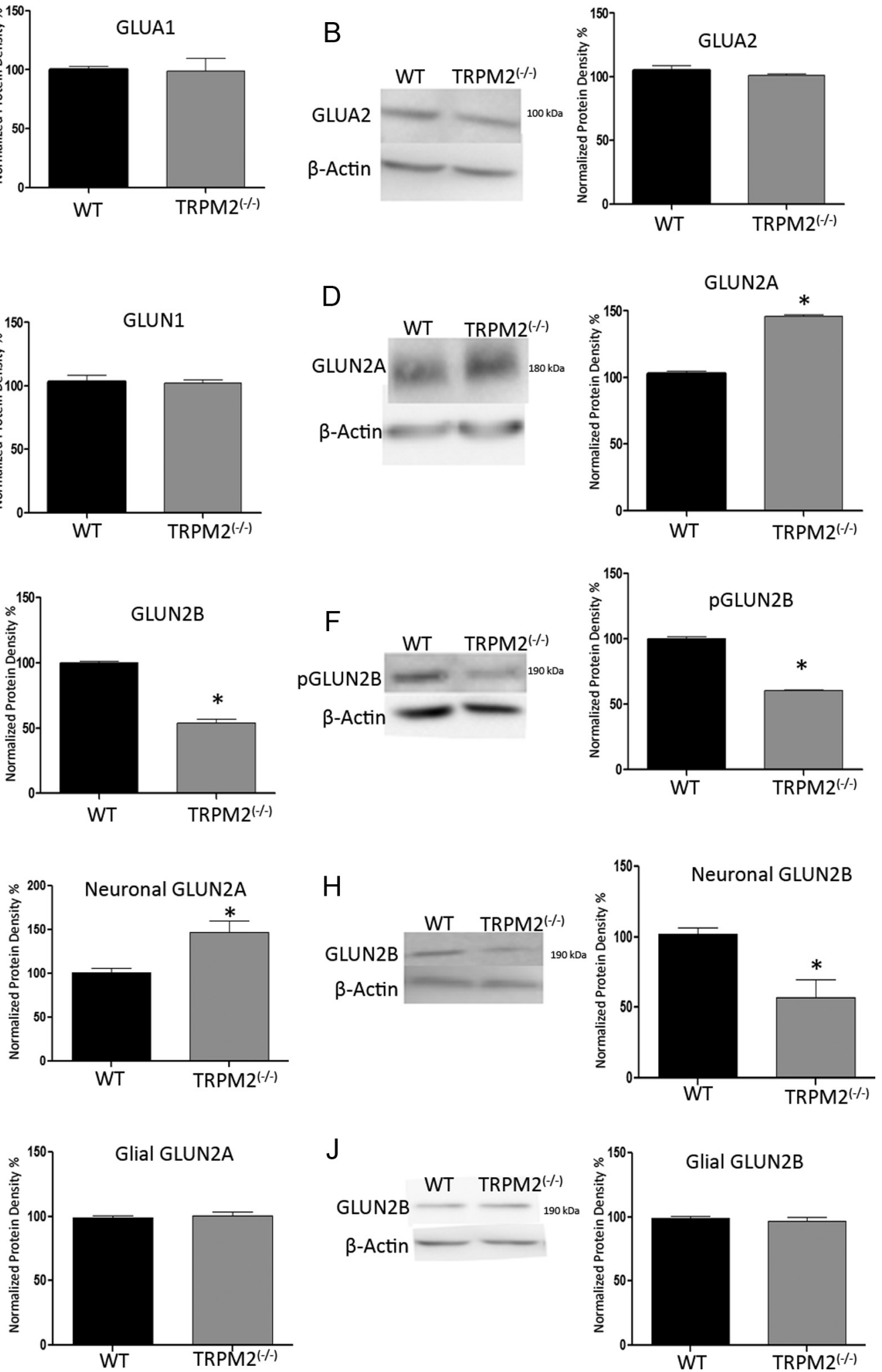

$\mathrm{H}$

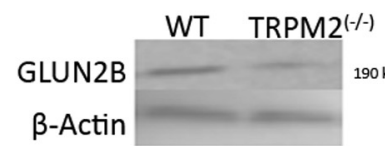

GLUN2A
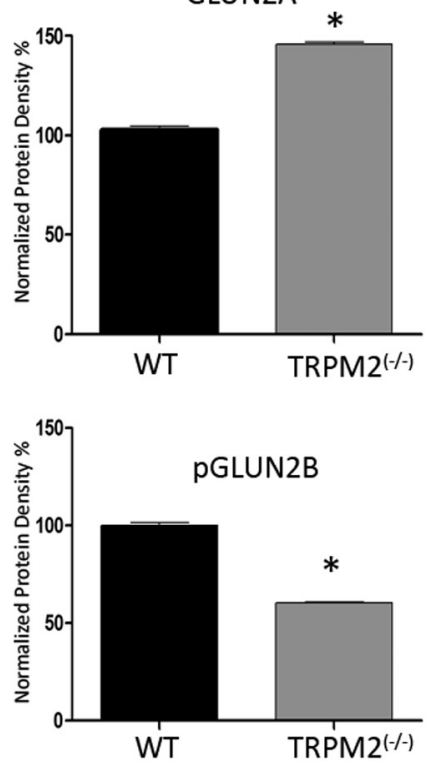

J
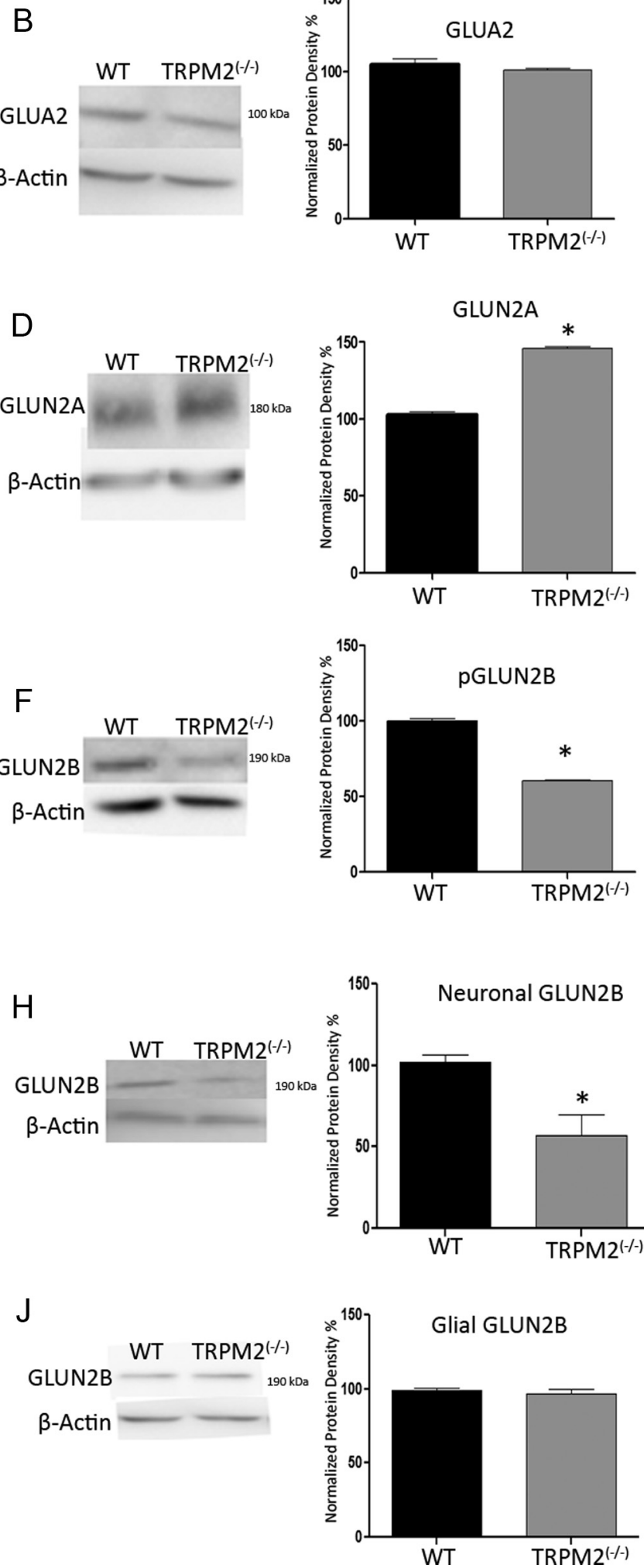

Figure 4. TRPM2 $2^{-1-}$ hippocampi have reduced GluN2B expression and increased GluN2A expression. Western blots detecting glutamate receptor expression in hippocampal protein extracts from 3- to 8-week-old TRPM2 ${ }^{-1-}$ and WT animals. $\boldsymbol{A}, \boldsymbol{B}$, Densitometry of protein expression of AMPA subunits GluA1 and GluA2 showed no significant difference between TRPM2 ${ }^{-1-}$ and WT ( $p>0.05 ; n=4$ blots with 3 samples of each genotype). C, NMDA subunit GluN1, which binds to GluN2 subunits, also did not have any significant change in protein expression, suggesting that total NMDAR is the same between TRPM2 ${ }^{-/-}$and WT hippocampi. D-F, However, protein expression of NMDAR GluN2 subunits did change, where basal GluN2A expression was increased by $43.30 \pm 2.33 \%$ in the TRPM2 $2^{-1-}$ (gray bar) compared with WT (black bar; $n=3 ; \boldsymbol{D}$ ). ${ }^{*} p<0.01$. Both basal and active GluN2B is reduced in TRPM2 ${ }^{-/-}$by $46.21 \pm 3.18 \%$ and $39.55 \pm 1.22 \%$, respectively, compared with WT $(n=3)(\boldsymbol{E}, \boldsymbol{F}) .^{*} p<0.01$. $\boldsymbol{G}, \boldsymbol{H}$, Western blots and densitometry of neuronal cultures from WT and TRPM2 ${ }^{-/-}$mice show that absence of TRPM2 increased GluN2A expression by $47.30 \pm 12.57 \%\left(n=3,{ }^{*} p<0.05\right)$ and decreased GluN2B expression by $43.66 \pm 12.44 \%\left(n=3,{ }^{*} p<0.05\right)$ compared with WT primary neuronal cultures. I,J, Primary glial cultures showed no change in GluN2A and GluN2B expression ( $n=3, p>0.05)$. 
TRPM $2^{-/-}$by $39.55 \pm 1.22 \%(n=3 ; p<0.01$; Fig. $4 F)$, suggesting that this reduction in basal expression of GluN2B subunit may also translate to a reduction in GluN2B function. The levels of GluN1 subunit protein, which binds to GluN2A and GluN2B, were unchanged ( $p>0.05$; Fig. $4 C$ ).

One limitation to using whole hippocampi for immunoblots is the difficulty in determining whether the observed change in GluN2 subunit expression levels is occurring in neurons or non-neuronal cell types. Therefore, we addressed this issue using protein extracts taken from primary hippocampal neuronal cultures. We found that neuronal cultures from TRPM $2^{-1-}$ animals exhibited an increased GluN2A expression by $47.30 \pm 12.57 \%(n=3 ; p<0.05$; Fig. $4 G)$ and a decreased GluN2B expression by $43.66 \pm 12.44 \%(n=3 ; p<$ 0.05; Fig. $4 H$ ), compared with neuronal cultures from WT animals. By contrast, repeating these experiments with protein extracts taken from primary glial cultures revealed that GluN2A and GluN2B levels were comparable between cultures from WT and TRPM $2^{-1-}$ animals $(n=3 ; p>0.05$; Fig. $4 I, J)$. These findings suggest that the deficiency of TRPM 2 results in marked alterations in the ratios of expressed GluN2A and GluN2B subunits in neurons, but not in glia, without affecting the overall expression of total NMDAR proteins. This raises the possibility of a previously unappreciated contribution of TRPM2 to the regulation of NMDAR subunit composition. Given that GluN2A subunits are generally localized in synapses and are associated with prosurvival signaling (Martel et al., 2009; Hardingham and Bading, 2010), our findings of an increased GluN2A/GluN2B ratio may explain how increased excitability during redox modulation imparts a reduced vulnerability to cerebral ischemia in the TRPM $2^{-/-}$animals.

To further interpret our findings, we examined whether the changes in GluN2A and GluN2B expression induced by the absence of TRPM2 can be visualized in hippocampal CA1 neurons. To this end, we measured the total number of GluN2A and GluN2B clusters and the synaptic colocalization of these clusters in individual dendrites of low-density cultures taken from the CA1 sectors of both WT and TRPM $2^{-1-}$ male animals. First, we found that CA1 neurons expressed each of GluN2A and GluN2B in both WT and TRPM2 ${ }^{-1-}$ neurons (Fig. $5 A, B$ ). By counting the numbers of clusters in GluN2A and GluN2B subunits, we found that the absence of TRPM2 caused a decrease in GluN2B clusters $(n=24$ dendritic segments; $p<0.05$; Fig. $5 F)$ and no change in GluN2A clusters $(n=27 ; p>0.05$; Fig. $5 C)$ compared with WT. Next, using the synaptic marker VGLUT to determine synaptic colocalization, we found that TRPM2 $2^{-1-}$ neurons exhibited a reduction in the number of synapses containing GluN2B compared with WT $(n=24 ; p<0.05$; Fig. $5 H)$, whereas there was no significant change in the number of synapses containing GluN2A $(n=27 ; p>0.05$; Fig. $5 E)$. These findings suggest that a chronic absence of TRPM 2 reduces the numbers of GluN2B clusters and GluN2B localization at the synapse, and thus changes the ratio of GluN2A to GluN2B-containing NMDARs at the synapse to promote signaling through GluN2Acontaining NMDARs.

\section{GluN2A is involved in $\mathrm{H}_{2} \mathrm{O}_{2}$-induced synaptic excitability in TRPM2 ${ }^{-1-}$ neurons}

Thus far, we have shown that chronic absence of TRPM2 results in increased excitability in hippocampal neurons in response to $\mathrm{H}_{2} \mathrm{O}_{2}$ and that synaptic GluN2A/GluN2B ratios are altered in a direction that may promote prosurvival signaling. We next explored whether the observed increase in GluN2A/GluN2B ratio was functionally related to the observed increase in excitability. As previously noted, bath application of $200 \mu \mathrm{M}$ of $\mathrm{H}_{2} \mathrm{O}_{2}$ increased excitability of CA-1 neurons in slices taken from $\mathrm{TRPM}^{-/-}$mice. However, an application of the GluN2Aselective antagonist PEAQX $(0.4 \mu \mathrm{M}$; $>10$-fold selectivity of GluN2A over GluN2B) (Auberson et al., 2002; Feng et al., 2005) 10 min after the $\mathrm{H}_{2} \mathrm{O}_{2}$ challenge significantly reduced the fEPSP slope, although fEPSPs did not return to the same baseline levels as in the absence of $\mathrm{H}_{2} \mathrm{O}_{2}(n=7 ; p<0.05$; Fig. $6 A)$. By contrast, the GluN2B-selective antagonist, RO25-6981 (0.5 $\mu \mathrm{M})$, had no effect on the $\mathrm{H}_{2} \mathrm{O}_{2}$-induced increased excitability in the TRPM2 ${ }^{-/-}$hippocampal slices (Fig. 6C). Neither the GluN2A nor the GluN2B antagonists affected baseline fEPSP slope in both the WT and TRPM2 $2^{-1-}$ hippocampus (Fig. 6B,D). Moreover, when antagonists were applied before the application of $\mathrm{H}_{2} \mathrm{O}_{2}$, the GluN2B antagonist did not inhibit the increase in fEPSP slope, whereas the GluN2A antagonist significantly blunted this increase in the TRPM $2^{-1-}$ neurons (Fig. $6 B, D$ ). These findings demonstrate that NMDARs containing the GluN2A subunit are responsible for mediating the increase in synaptic excitability observed when TRPM2 ${ }^{-1-}$ hippocampal neurons are subjected to an $\mathrm{H}_{2} \mathrm{O}_{2}$ challenge and that this phenomenon is paralleled by an increase in GluN2A expression in the absence of TRPM2. It should be noted that the GluN2A-specific antagonist does not completely inhibit the increase in synaptic excitability due to $\mathrm{H}_{2} \mathrm{O}_{2}$, suggesting that other channels may still be involved.

\section{Absence of TRPM2 provides neuroprotection by modulating GluN2A activity}

We have demonstrated that TRPM2-null mice have reduced infarct volume after tMCAO, compared with WT mice, and this is attributable to changes in GluN2A and GluN2B expression in neurons. To confirm these in vivo observations in a simpler system, we evaluated the impact of TRPM 2 on the vulnerability of primary hippocampal neuronal cultures to OGD. We found that cultures from TRPM $2^{-1-}$ mice sustained reduced neuronal death after a $1 \mathrm{~h}$ OGD compared with cultures from WT animals $(n=8$ wells; $p<0.01$; Fig. $6 E)$. Adding catalase $(30-300 \mathrm{U} / \mathrm{ml})$ to decompose $\mathrm{H}_{2} \mathrm{O}_{2}$ reduced neuronal death in cultures from WT mice after 1 h OGD compared with untreated WT cultures $(n=$ $8 ; p<0.01$; Fig. $6 E$ ) and had no effect on the neuroprotection in TRPM2-null cultures, suggesting that $\mathrm{H}_{2} \mathrm{O}_{2}$ plays a role in OGDinduced neuronal death. Application of the known GluN2Aselective antagonists, PEAQX (0.4 $\mu \mathrm{M}$; Auberson et al., 2002) or TCN201 (10 $\mu \mathrm{M}$; Bettini et al., 2010) during a 1 h OGD eliminated the neuroprotection observed in TRPM2-null cultures $(n=8 ; p<0.01$; Fig. $6 E)$, with no effect on WT cultures. This further confirms that NR2A subunits are key to mediating the enhanced resilience of TRPM2-null neurons to OGD. Because TCN201 was dissolved in DMSO, we also tested the effect of vehicle on WT and TRPM $2^{-1-}$ cultures and found that DMSO has no effect on neuronal survival when compared with untreated conditions (Fig. 6E). Application of GluN2B-selective antagonists, RO25-6981 (0.5 $\mu \mathrm{M})$ and Co101244 (0.5 $\mu \mathrm{M}$; Stanika et al., 2009), during $1 \mathrm{~h}$ OGD reduced death in neurons from WT mice compared with untreated WT cultures $(n=8 ; p<0.01)$ but had no effect on the neuroprotection observed in TRPM2-null cultures $(n=8 ; p>0.05$; Fig. $6 E)$. This confirms that inhibition of GluN2B-containing NMDARs is neuroprotective and suggests that, because of the already low levels of GluN2B in TRPM2 $2^{-1-}$ neuronal cultures, blocking GluN2B does not provide additional neuroprotection in neurons that lack TRPM2 channels. Overall, these findings suggest that, in vitro, $1 \mathrm{~h}$ OGD mediates neuronal 
A
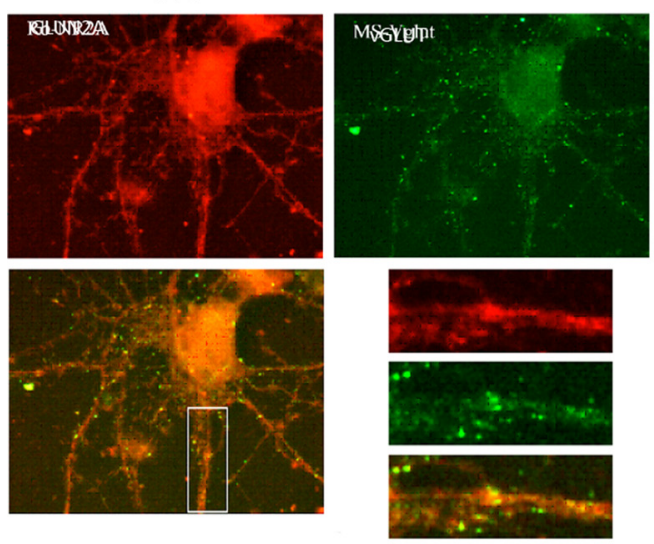

B
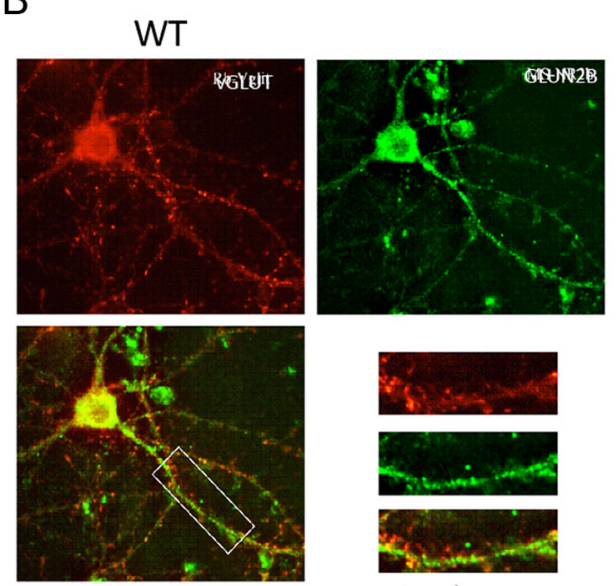

TRPM2 $2^{(--)}$
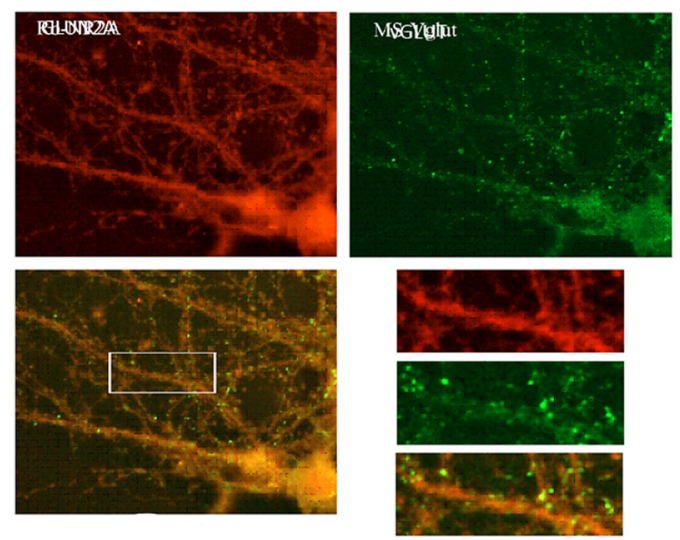

TRPM2 $2^{(-/)}$
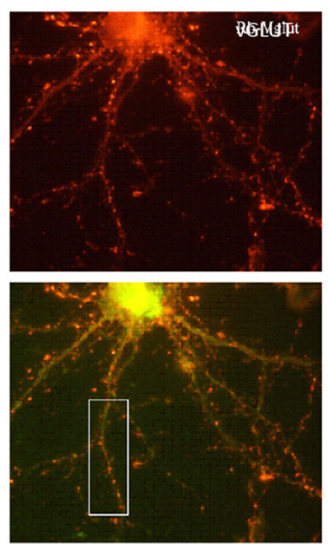
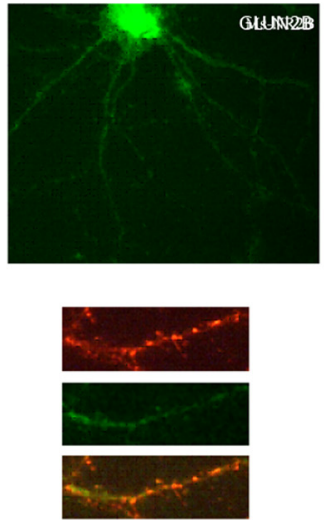

C

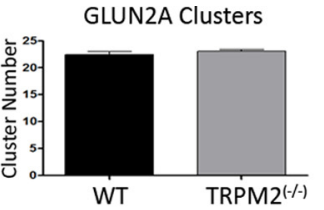

D
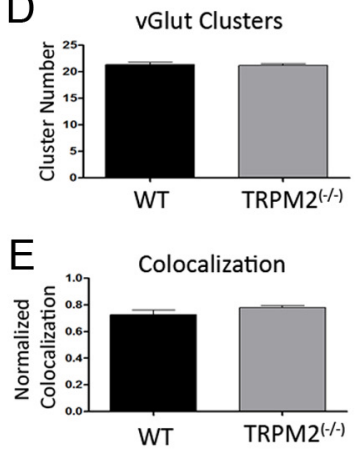

F

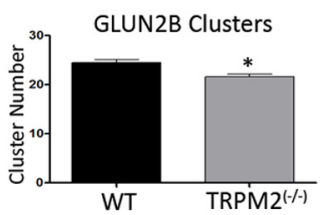

G

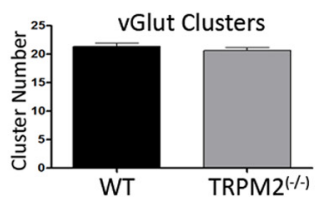

$\mathrm{H}$

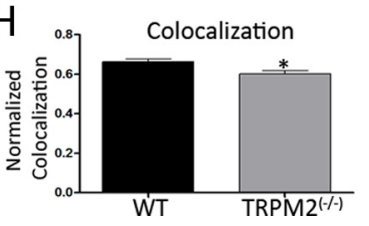

Figure 5. TRPM2 ${ }^{-1-}$ reduces synaptic colocalization of GluN2B, but not GluN2A. Immunofluorescence of detecting GluN2A and GluN2B clusters in hippocampal CA1 neurons from WT and TRPM2 $^{-1-}$ animals. $A$, To detect synaptic GluN2A, equal dendritic segments were used to count labeled clusters, where green fluorescence represents synaptic marker VGLUT expression and red represents GluN2A subunit expression. $\boldsymbol{B}$, Synaptic GluN2B are labeled as follows: red fluorescence is VGLUT, and green is GluN2B. Overlaid images were used to count colocalized clusters. $C$, WT and TRPM2 ${ }^{-1-}$ had no difference in number of GluN2A clusters $(n=27 ; p>0.05)$. $\boldsymbol{D}, \boldsymbol{E}$, There was also no change in number of synapse and GluN2A synaptic colocalization between neurons from WT and TRPM2 ${ }^{-1-}$ animals $(n=27 ; p>0.05)$. $\boldsymbol{F}$, The number of GluN2B clusters were reduced in hippocampal neurons from TRPM2 ${ }^{-1-}$ animals compared with those from WT animals $(n=24)$. ${ }^{*} p<0.05 . \mathbf{G}, \boldsymbol{H}, \mathrm{GluN2B}$ synaptic colocalization was also reduced in TRPM2-null neurons compared with WT ( $n=24 ;{ }^{*} p<0.05$ ), with no effect on total number of synapses. $\boldsymbol{H}$, Colocalization of GluN2B and VGLUT was reduced in TRPM2 ${ }^{-1-}$ compared with WT.

death in cultures from WT animals through $\mathrm{H}_{2} \mathrm{O}_{2}$ and GluN2B subunit activity, whereas primary neuronal cultures that lack TRPM2 channels are more resilient to OGD through the activity of GluN2A-containing NMDARs.

\section{The absence of TRPM2 increases Akt and ERK activity}

A shift in GluN2A/GluN2B expression and activity levels in normal cells can result in the activation of prosurvival downstream pathways that allows neurons to become preconditioned for reduced ischemic vulnerability. An increase in the activity of GluN2A-containing NMDARs is known to increase the phosphorylation of Akt and ERK (Hardingham et al., 2001; Papadia et al., 2005; Hardingham, 2006), leading to the promotion of prosurvival mechanisms in the cell. By contrast, an increase in the activity of GluN2B-containing NMDARs inhibits prosurvival mechanisms (Y. Liu et al., 2007; Soriano et al., 2008). Using Western blots from whole hippocampi dissected from WT and TRPM $2^{-1-}$ mice, we found that the basal expression levels of Akt and ERK proteins were similar in both (Fig. $7 A, D$ ). However, upon comparing the levels of the active (phosphorylated) form of Akt and ERK, there was an increase in both phospho-Akt (by $49.39 \pm 8.26 \%$ in Ser- $473 ; 65.11 \pm 13.78 \%$ in Thr-308; $n=4 ; p<$ 0.01 ) and phospho-ERK (by $76.44 \pm 23.12 \% ; n=4 ; p<0.01$ ), respectively, in the TRPM $2^{-1-}$ hippocampus (Fig. $7 B, C, E$ ), suggesting that the absence of TRPM2 activates these prosurvival signaling proteins.

Glycogen synthase kinase (GSK3 $\beta$ ) is an important target of Akt, which is involved with mitochondrial BAX translocation during apoptosis (Linseman et al., 2004). Akt is involved in neuroprotection by inhibiting GSK3 $\beta$ via phosphorylation of serine 9 (Crowder and Freeman, 2000; Hetman et al., 2000). If TRPM $2^{-1-}$ is neuroprotective via by upregulating NMDAR subunits associated with prosurvival signaling, then Akt should be inhibiting GSK3 $\beta$ through its phosphorylation. Compatible with this hypothesis, we found, using Western blots that in TRPM $2^{-1-}$ hippocampi, there was a $38.96 \pm 4.97 \%(n=3 ; p<$ 

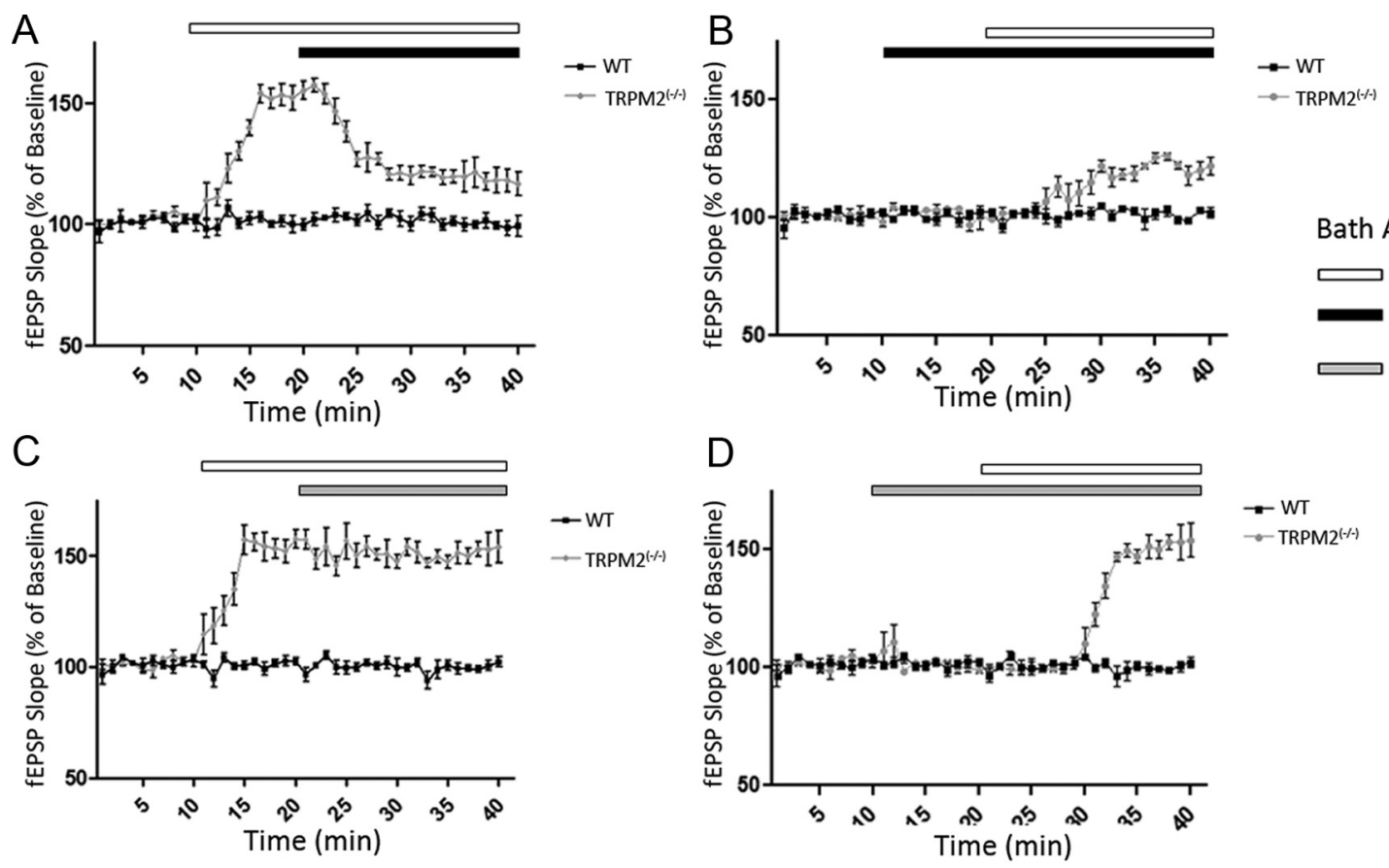

Bath Applied

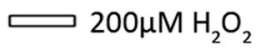

$0.4 \mu \mathrm{M}$ PEAQX

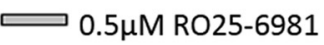

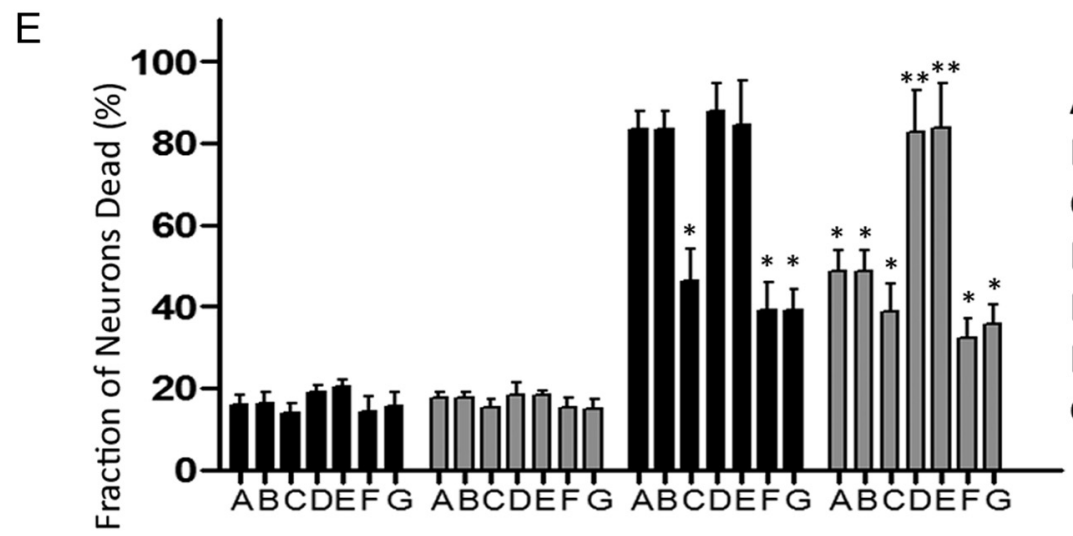

A: HBSS (Control)

B: DMSO $(0.01 \%)$

C: Catalase $(30-300 \mathrm{U} / \mathrm{ml})$

D: $0.4 \mu \mathrm{M}$ PEAQX (GluN2A blocker)

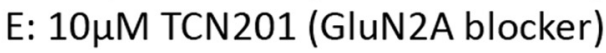

F: 0.5 $\mu \mathrm{M}$ RO25-6981 (GluN2B blocker)

G: $0.5 \mu \mathrm{M}$ Co101244 (GluN2B blocker)

WT

TRPM2 $2^{(-H)}$

Figure 6. GluN2A modulates $\mathrm{H}_{2} \mathrm{O}_{2}$-induced excitability in TRPM2 ${ }^{-1-}$ hippocampal neurons. fEPSPs evoked by stimulating Schaffer collaterals $(100-200 \mu \mathrm{A})$ were measured in the CA1 hippocampal dendritic region in slices from TRPM2 ${ }^{-1-}$ and WT animals. $A$, After 10 min of baseline fEPSP recording, $200 \mu \mathrm{M} \mathrm{H}_{2} \mathrm{O}_{2}$ (white bar) was applied to induce an increase in fEPSP slope in TRPM2-null slices, with no effect on WT (as described earlier). Bath application of GluN2A-specific antagonist ( $0.4 \mu \mathrm{M}$ of PEAQX, black bar) at 20 min reduced the $\mathrm{H}_{2} \mathrm{O}_{2}$-induced increase in fEPSP slope in TRPM2 ${ }^{-1-}$ slices $(n=7 p<0.05)$, with no effect on WT. $B$, When GluN2A-specific antagonist was applied at 10 min without $\mathrm{H}_{2} \mathrm{O}_{2}$, there was no change in baseline fEPSP slope in both WT and TRPM2 $^{-1-}$ slices. At $20 \mathrm{~min}, 200 \mu \mathrm{M} \mathrm{H}_{2} \mathrm{O}_{2}$ was applied, resulting in a smaller increase (compared with $\mathrm{H}_{2} \mathrm{O}_{2}$ only) in fEPSP slope in TRPM2 ${ }^{-1-}$ slices and had no effect in WT. C, Application of GluN2B-specific antagonist ( $0.5 \mu \mathrm{M} \mathrm{RO256981}$, gray bar) after 10 min of $200 \mu \mathrm{M} \mathrm{H}_{2} \mathrm{O}_{2}$ had no effect on the $\mathrm{H}_{2} \mathrm{O}_{2}$-induced increase in fEPSP slope seen in TRPM2 ${ }^{-I-}$ slices $(n=7)$. D, GluN2B-specific antagonist, when applied before $\mathrm{H}_{2} \mathrm{O}_{2}$ application, had no effect on baseline fEPSP slope $(n=7)$ in both TRPM2 ${ }^{-1-}$ and WT slices, nor did it have any effect on oxidative stress-induced excitability in TRPM2 ${ }^{-1-}$ slices when $\mathrm{H}_{2} \mathrm{O}_{2}$ was applied. All compounds were diluted in ACSF. $E$, After $1 \mathrm{~h} \mathrm{OGD}$, neuronal cultures from TRPM2 ${ }^{-1-}$ mice had reduced cell death compared with cultures from WT $\left(p<0.01\right.$ ). The neuroprotection from the lack of TRPM2 was inhibited by application of GluN2A-specific antagonists (PEAQX and TCN201). In WT cultures, catalase, which breaks down $\mathrm{H}_{2} \mathrm{O}_{2}$, and GluN2B-specific antagonists (R025-6981 and C0101244) provided neuroprotection after $1 \mathrm{~h}$ OGD. DMSO vehicle had no effect on survival of WT or TRPM2 ${ }^{-1-}$ cultures. $^{*}$ Significant difference from WT HBSS (control) $1 \mathrm{~h} \mathrm{OGD.}{ }^{*}$ Significant difference from TRPM2 ${ }^{-1-}$ HBSS (control) $1 \mathrm{~h}$ OGD.

0.01 ) increase in phospho-GSK3 $\beta$ compared with WT (Fig. $7 F$ ). These findings suggest that TRPM $2^{-1-}$ is neuroprotective via the Akt-pathway, by inhibiting downstream GSK3 $\beta$.

Postsynaptic density 95 (PSD-95) is known to interact with GluN2B and is involved in maintaining GluN2B surface clustering (Chung et al., 2004) and in signaling pathways associated with neuronal death (Sattler et al., 1999; Aarts et al., 2002). Because TRPM $2^{-1-}$ results in a reduction of GluN2B clustering in hippocampal neurons, we questioned whether it might also inhibit the expression of PSD-95. To determine this, we used whole hippocampus for Western blots and found that the absence of TRPM2 resulted in a $45.61 \pm 12.76 \%(n=3 ; p<0.01)$ reduction in PSD-95 expression compared with WT (Fig. $7 G$ ). The reduc- tion of PSD-95 and GluN2B further suggests that TRPM2 ${ }^{-/-}$ inhibits both GluN2B clustering and prodeath signaling.

Neuroprotection by preconditioning with NMDA has been shown to cause a rapid release in BDNF, which activates postsynaptic BDNF receptor TRKB (Jiang et al., 2005). We used Western blots to determine whether TRPM $2^{-1-}$ is involved in regulating BDNF release leading to neuroprotection. The phosphorylation of TRKB was the same between WT and TRPM $2^{-1-}$ hippocampus (Fig. $7 H$ ), suggesting that TRPM2 does not play a role in BDNF-mediated neuroprotection.

Our experiments indicate that, with the modulation of GluN2A and GluN2B by TRPM2, there is a shift of NR2A/ $\mathrm{NR} 2 \mathrm{~B}$ ratio and activity that results in the selective activation 
A

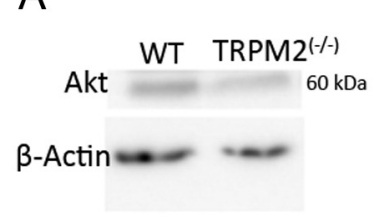

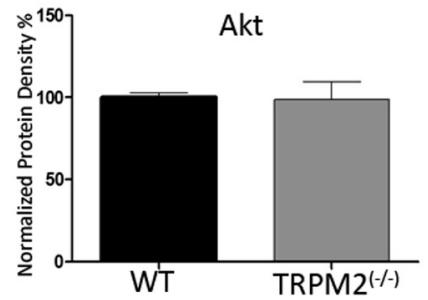

B

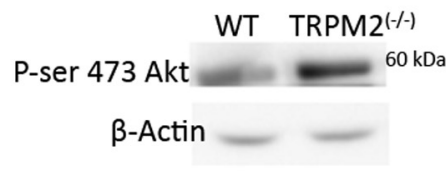

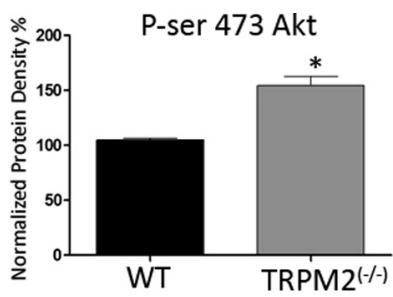

D
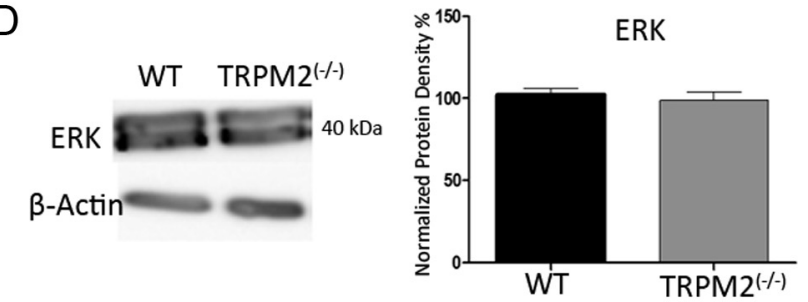

$\mathrm{F}$

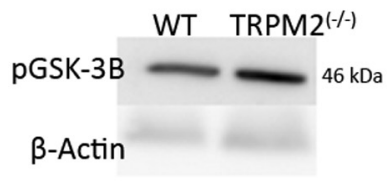

G

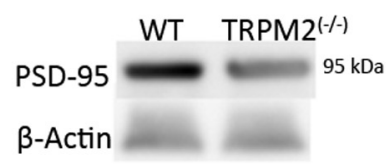

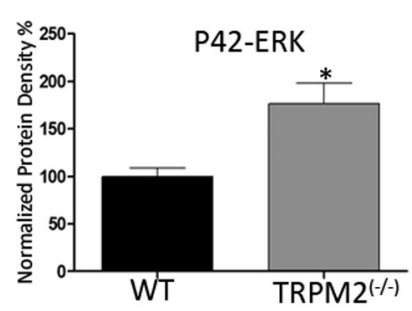

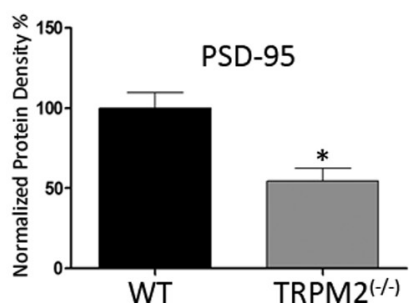

$\mathrm{H}$

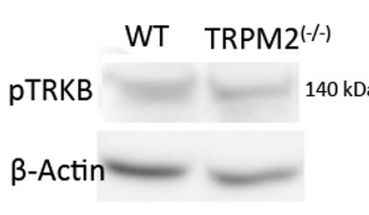

Figure 7. TRPM2 ${ }^{-1-}$ increases activity in ERK and Akt pathways. Western blots of whole hippocampi from WT and TRPM2 ${ }^{-1-}$ animals detecting changes in expression of proteins responsible for downstream NMDAR-mediated cell survival mechanisms. $A$, Basal levels of Akt had no change in expression between WT and TRPM2 ${ }^{-1-}$. B, $C$, However, phospho-Akt was increased at both phosphorylation sites ( $49.39 \pm 8.26 \%$ in Ser- $473 ; 65.11 \pm 13.78 \%$ in Thr-308; $n=4 ;{ }^{*} p<0.01$ ) in TRPM2 ${ }^{-1-}$ hippocampi compared with WT. $\boldsymbol{D}$, There was no change in the basal ERK protein expression comparing WT and TRPM2 ${ }^{-I-}$ hippocampi. $\boldsymbol{E}$, Active ERK was increased by $76.44 \pm 23.12 \%\left(n=4 ;{ }^{*} p<0.01\right)$ in TRPM2 ${ }^{-I-}$ compared with WT. $\boldsymbol{F}$, GSK3 $\beta$ is phosphorylated by Akt; in TRPM2 ${ }^{-1-}$ hippocampi, there was a $38.96 \pm 4.97 \%\left(n=3 ;{ }^{*} p<0.01\right)$ increase in phosphorylation of GSK3 $\beta$ compared with WT. G, PSD-95 protein expression was decreased by $45.61 \pm$ $12.76 \%\left(n=3{ }^{*} p<0.01\right)$ in hippocampus from TRPM2 ${ }^{-l-}$ animals compared with WT. $\boldsymbol{H}$, BDNF-mediated TRKB phosphorylation, which is known to be involved in NMDA-mediated neuroprotection, was not affected by the absence of TRPM2 $(n=3)$. Together, these results show that the absence of TRPM2 promotes prosurvival pathways in the hippocampus.

of prosurvival pathways in TRPM2 $2^{-1-}$ neurons. Specifically, TRPM $2^{-1-}$ neurons exhibit an increase in the expression and activity of synaptic GluN2A-containing NMDARs, leading to a concomitant increase in prosurvival Akt and ERK pathways acting, at least in part, through inhibition of the proapoptotic factor GSK3 $\beta$. Also, the lack of TRPM2 causes a reduction in the expression of GluN2B and of PSD-95, both of which are implicated in prodeath signaling (Aarts et al., 2002). Thus, TRPM2 may represent a newly identified hub that modulates NMDAR-dependent prosurvival and prodeath mechanisms.

\section{Discussion}

Here we used TRPM $2^{-1-}$ mice to describe a novel mechanism of the regulation of cell death by TRPM2 after an ischemic insult.
Using an in vivo stroke model, we showed that the absence of TRPM2 is neuroprotective when ischemia is followed by reperfusion. In hippocampal slices, we found that a sublethal challenge with the oxidant $\mathrm{H}_{2} \mathrm{O}_{2}$ increases baseline synaptic excitability in CA1 neurons from TRPM2 ${ }^{-l-}$ but not WT neurons. This increase in excitability was the result of a reduction in GluN2B and an increase in GluN2A expression levels in TRPM2 ${ }^{-1-}$ mouse neurons, and a concomitant reduction in the numbers of GluN2B-containing synaptic clusters in CA1 hippocampal neurons. By contrast, GluN2A-containing NMDARs were increased at synapses. The $\mathrm{H}_{2} \mathrm{O}_{2}$-induced increase in excitability of TRPM2 ${ }^{-1-}$ neurons depended on GluN2A-containing NMDARs as it was blocked by a GluN2A-specific antagonist. Additionally, in vitro neuroprotection provided by the absence of 


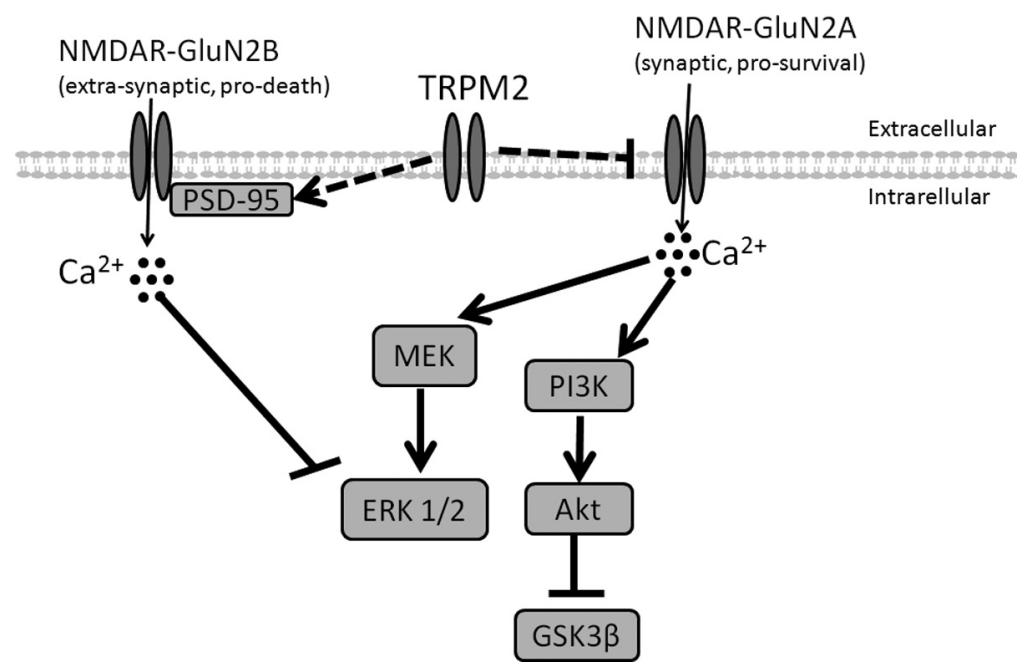

Figure 8. Proposed mechanism of cell death involving TRPM2. The expression of TRPM2 is required to promote expression of PSD-95 and inhibit GluN2A subunit of NMDA receptors. PSD-95 is responsible for transporting GluN2B-containing NMDAR to the cell surface and activating GluN2B by binding. When PSD95 activates GluN2B-containing NMDAR, there is an influx of extrasynaptic $\mathrm{Ca}^{2+}$, which leads to inhibition of phosphorylation of ERK1/2 and promotes cell death. The inhibition of GluN2A expression reduces synaptic $\mathrm{Ca}^{2+}$ influx and prevents downstream activation of MEK and PI3 kinases, which are required for phosphorylation of ERK1/2 and Akt, respectively. Phosphorylation of Akt inhibits proapoptotic factor GSK3 $\beta$. Overall, TRPM2 channel inhibits expression of prosurvival NMDARs and increases expression of prodeath NMDARs.

TRPM2 was blocked by GluN2A-specific antagonists. The changes in GluN2A and GluN2B expression led to an increase in the activation of the Akt and ERK pathways, both of which led to activation of prosurvival mechanisms (Hardingham et al., 2001, 2006; Papadia et al., 2005). Our findings suggest a novel view of cell death after ischemia, in which TRPM2 expression is required for GluN2B expression and plays a role in inhibiting GluN2A. The alterations of GluN2A/GluN2B ratios or levels impacts downstream Akt and ERK pathways leading to a promotion of prodeath and inhibition of prosurvival mechanisms (Fig. 8). Overall, this study suggests that TRPM2 is part of a regulatory hub for NMDAR-dependent prosurvival and prodeath mechanisms.

TRPM2 was initially implicated to play a role in ischemic cell death because it is activated by products of oxidative stress, specifically $\mathrm{H}_{2} \mathrm{O}_{2}$ (Hara et al., 2002) and ADPR (Perraud et al., 2005). It is thought that overproduction of $\mathrm{H}_{2} \mathrm{O}_{2}$ and $\mathrm{ADPR}$ leads to the activation of TRPM2, which would contribute to $\mathrm{Ca}^{2+}$ overload (Olah et al., 2009; Tymianski, 2011). Inhibition of TRPM2, using antagonists and by gene silencing, is known to inhibit ADPR and $\mathrm{H}_{2} \mathrm{O}_{2}$-induced $\mathrm{Ca}^{2+}$ influx (Hara et al., 2002; Harteneck et al., 2007; Olah et al., 2009). Attempts to determine whether TRPM2 inhibition is neuroprotective during oxidative stress conditions have led to conflicting results, whereby gene silencing provides neuroprotection in cortical neurons (Kaneko et al., 2006), but nonspecific TRPM2 antagonists do not in the hippocampus (Bai and Lipski, 2010). A recent study has shown that susceptibility to neuroprotection by TRPM2 inhibition may be sex-dependent, such that, after ischemic conditions, TRPM2 inhibition is neuroprotective in neurons from males, but not those from females (Jia et al., 2011). However, in this study, we conducted experiments in neuronal cultures derived from both male and female animals, as well as from cultures from only male WT and TRPM $2^{-1-}$ mice only. These provided similar results (data not shown); therefore, we did not observe a difference in neuroprotective effects of the absence of TRPM 2 in both maleonly and mixed gender cultures.
With the development of a TRPM $2^{-1-}$ mouse, studies in monocytes and in hippocampal neurons have shown that the absence of TRPM2 also results in a reduction of TRPM2-like $\mathrm{Ca}^{2+}$ currents (Yamamoto et al., 2008; Xie et al., 2011). Thus, this mouse model was useful to study the effects of a chronic absence of TRPM2 on ischemia and reperfusion in vivo. We note that neuroprotection in TRPM $2^{-1-}$ may not be solely the result of an absence of TRPM2 function but also changes in NMDAR expression, and perhaps this phenomenon may not be observed in acute TRPM2 inhibition.

Because NMDARs play a role in both cell survival and cell death (Hardingham and Bading, 2003), it is possible that this duality is the reason why completely blocking NMDAR failed to provide neuroprotection in stroke patients during clinical trials (Davis et al., 1997; Lees et al., 2000; Ikonomidou and Turski, 2002). A number of studies have identified that the GluN2A and GluN2B NMDAR subunits are responsible for determining prosurvival and prodeath functions, respectively, in neurons (Soriano et al., 2006; Y. Liu et al., 2007; Terasaki et al., 2010). Here we show that TRPM2 is required for the upregulation of the NMDA subunit GluN2B and the downregulation of the GluN2A subunit, which conditions primes neurons for cell death. Unfortunately, it is currently unclear how and when TRPM2 modulates NMDA subunit expression. It is well known that, during early brain development, GluN2B-containing NMDARs are predominantly expressed in the prenatal and early postnatal brain, whereas GluN2A expression begins shortly before birth and eventually the GluN2A subunit outnumbers GluN2B (Monyer et al., 1994; Wenzel et al., 1997). This phenomenon is known as the GluN2BGluN2A developmental switch. Because the adult GluN2BGluN2A ratio is established during postnatal brain development (Wenzel et al., 1997), it is possible that TRPM2 may play a role in modulating the GluN2B-GluN2A developmental switch. Furthermore, because PSD-95 may be required for GluN2B trafficking (Chung et al., 2004), it is conceivable that, during development, TRPM2 may regulate GluN2B expression by influencing PSD-95 expression, which in turn would affect the GluN2B-GluN2A developmental switch.

During ischemic cell death, intracellular $\mathrm{Ca}^{2+}$ levels rise, leading to mitochondrial dysfunction, which overproduces ROS that further activates glutamate and nonglutamate $\mathrm{Ca}^{2+}$ channels (Arundine and Tymianski, 2004). The production of ROS occurs primarily during reperfusion (Chan, 1996), and ROS have been shown to influence a number of cellular mechanisms, particularly synaptic activity (Kamsler and Segal, 2003; Maalouf and Rho, 2008). A lack of TRPM2 has no effect on the formation of LTP or on the inhibition of LTP by $200 \mu \mathrm{M} \mathrm{H}_{2} \mathrm{O}_{2}$. However, $\mathrm{H}_{2} \mathrm{O}_{2}$ does cause an increase in synaptic excitability in hippocampal CA1 neuron TRPM2 ${ }^{-1-}$ mice with no effect on WT. This sensitivity to $\mathrm{H}_{2} \mathrm{O}_{2}$ in the absence of TRPM 2 was partially inhibited by a GluN2A-specific inhibitor. How TRPM2 $2^{-1-}$ neurons become sensitive to $\mathrm{H}_{2} \mathrm{O}_{2}$ remains unclear; however, it is possible that an absence of TRPM2-mediated calcium influx leads to a hypersensitization of glutamate receptors (specifically containing 
GluN2A) and other cation channels to $\mathrm{H}_{2} \mathrm{O}_{2}$, ultimately leading to increased synaptic excitability.

A recent study using hippocampus from TRPM $2^{-1-}$ animals has shown that an absence of TRPM2 leads to inhibition of longterm depression via phosphorylation of GSK3 $\beta$, and modulation of PSD-95 and AMPA subunit GluA1, with no change to NMDAR subunits GluN2A and GluN2B (Xie et al., 2011). We also show here that, in TRPM2 ${ }^{-1-}$ hippocampus, there is a reduction in PSD-95 and an increase in phosphorylation of GSK3B. However, we did not detect any changes in AMPA receptors and instead found that a lack of TRPM2 modulates GluN2A and GluN2B expression. These findings are consistent with previous studies showing that NMDAR activity modulates GSK-3B via Akt signaling pathway (Soriano et al., 2006). Together, this suggests that TRPM2 plays a complex role in regulating the expression of a number of glutamate receptors.

Although this study provided some interesting insight into the role TRPM2 plays after ischemia, a number of caveats should be considered. First, the absence of TRPM2 had no effect on infarct volume in $24 \mathrm{~h} \mathrm{pMCAO}$, which would suggest that either TRPM2 is involved in cell death during reperfusion or that the pMCAO was so severe that any cytoprotective effects of TRPM2 deficiency were not detectable. Next, we saw that $200 \mu \mathrm{M}$ of $\mathrm{H}_{2} \mathrm{O}_{2}$ had inhibited LTP formation in TRPM $2^{-1-}$ and WT, which would mean that either TRPM2 $2^{-1-}$ has no effect on the inhibition of LTP by $\mathrm{H}_{2} \mathrm{O}_{2}$ or that the increase in baseline fEPSP induced by $\mathrm{H}_{2} \mathrm{O}_{2}$ in TRPM2 ${ }^{-/-}$results in a ceiling effect, thus preventing any additional potentiation. Removal of $\mathrm{H}_{2} \mathrm{O}_{2}$ after LTP induction in TRPM2 $2^{-1-}$ results in a return to baseline without $\mathrm{H}_{2} \mathrm{O}_{2}$, indicating that a ceiling effect is unlikely. Finally, significant increases in GluN2A expression were seen in Western blots without any effect on GluN2A synaptic colocalization; this may be because GluN2A maintains more concentrated but similar synaptic clustering in TRPM $2^{-1-}$ neurons compared with WT or changes in GluN2A expression were predominantly not at the synapse.

Overall, this study provides a novel mechanism on how a chronic absence of TRPM2 results in neuroprotection through a shift in the expression of NMDAR subunit subtypes. The findings we presented raise some interesting questions about how TRPM2 might be targeted for therapeutic interventions after ischemia. It is presently unknown whether acutely blocking TRPM2 will have a similar effect on NMDAR expression. Therefore, a fuller understanding of how TRPM2 regulates NMDARs and potentially other channels is required.

\section{References}

Aarts MM, Tymianski M (2005) TRPMs and neuronal cell death. Pflugers Arch 451:243-249. CrossRef Medline

Aarts M, Liu Y, Liu L, Besshoh S, Arundine M, Gurd JW, Wang YT, Salter MW, Tymianski M (2002) Treatment of ischemic brain damage by perturbing NMDA receptor-PSD-95 protein interactions. Science 298:846850. CrossRef Medline

Aarts M, Iihara K, Wei WL, Xiong ZG, Arundine M, Cerwinski W, MacDonald JF, Tymianski M (2003) A key role for TRPM7 channels in anoxic neuronal death. Cell 115:863-877. CrossRef Medline

Arundine M, Tymianski M (2004) Molecular mechanisms of glutamatedependent neurodegeneration in ischemia and traumatic brain injury. Cell Mol Life Sci 61:657-668. CrossRef Medline

Auberson YP, Allgeier H, Bischoff S, Lingenhoehl K, Moretti R, Schmutz M (2002) 5-Phosphonomethylquinoxalinediones as competitive NMDA receptor antagonists with a preference for the human $1 \mathrm{~A} / 2 \mathrm{~A}$, rather than 1A/2B receptor composition. Bioorg Med Chem Lett 12:1099-1102. CrossRef Medline

Bai JZ, Lipski J (2010) Differential expression of TRPM2 and TRPV4 channels and their potential role in oxidative stress-induced cell death in organotypic hippocampal culture. Neurotoxicology 31:204-214. CrossRef Medline
Barber PA, Hoyte L, Colbourne F, Buchan AM (2004) Temperature-regulated model of focal ischemia in the mouse: a study with histopathological and behavioral outcomes. Stroke 35:1720-1725. CrossRef Medline

Bederson JB, Pitts LH, Tsuji M, Nishimura MC, Davis RL, Bartkowski H (1986) Rat middle cerebral-artery occlusion: evaluation of the model and development of a neurologic examination. Stroke 17:472-476. CrossRef Medline

Besancon E, Guo S, Lok J, Tymianski M, Lo EH (2008) Beyond NMDA and AMPA glutamate receptors: emerging mechanisms for ionic imbalance and cell death in stroke. Trends Pharmacol Sci 29:268-275. CrossRef Medline

Bettini E, Sava A, Griffante C, Carignani C, Buson A, Capelli AM, Negri M, Andreetta F, Senar-Sancho SA, Guiral L, Cardullo F (2010) Identification and characterization of novel NMDA receptor antagonists selective for NR2A- over NR2B-containing receptors. J Pharmacol Exp Ther 335: 636-644. CrossRef Medline

Bischofberger J, Engel D, Li L, Geiger JR, Jonas P (2006) Patch-clamp recording from mossy fiber terminals in hippocampal slices. Nat Protoc 1:2075-2081. CrossRef Medline

Bliss TV, Collingridge GL (1993) A synaptic model of memory: long-term potentiation in the hippocampus. Nature 361:31-39. CrossRef Medline

Chan PH (1996) Role of oxidants in ischemic brain damage [review]. Stroke 27:1124-1129. CrossRef Medline

Chen M, Lu TJ, Chen XJ, Zhou Y, Chen Q, Feng XY, Xu L, Duan WH, Xiong ZQ (2008) Differential roles of NMDA receptor subtypes in ischemic neuronal cell death and ischemic tolerance. Stroke 39:3042-3048. CrossRef Medline

Chung HJ, Huang YH, Lau LF, Huganir RL (2004) Regulation of the NMDA receptor complex and trafficking by activity-dependent phosphorylation of the NR2B subunit PDZ ligand. J Neurosci 24:10248-10259. CrossRef Medline

Colton CA, Fagni L, Gilbert D (1989) The action of hydrogen-peroxide on paired pulse and long-term potentiation in the hippocampus. Free Radic Biol Med 7:3-8. CrossRef Medline

Crowder RJ, Freeman RS (2000) Glycogen synthase kinase-3 beta activity is critical for neuronal death caused by inhibiting phosphatidylinositol 3-kinase or Akt but not for death caused by nerve growth factor withdrawal. J Biol Chem 275:34266-34271. CrossRef Medline

Davis SM, Albers GW, Diener HC, Lees KR, Norris J (1997) Termination of acute stroke studies involving selfotel treatment. Lancet 349:32. CrossRef Medline

Feng B, Morley RM, Jane DE, Monaghan DT (2005) The effect of competitive antagonist chain length on NMDA receptor subunit selectivity. Neuropharmacology 48:354-359. CrossRef Medline

Friedman WJ (2000) Neurotrophins induce death of hippocampal neurons via the p75 receptor. J Neurosci 20:6340-6346. Medline

Hara Y, Wakamori M, Ishii M, Maeno E, Nishida M, Yoshida T, Yamada H, Shimizu S, Mori E, Kudoh J, Shimizu N, Kurose H, Okada Y, Imoto K, Mori Y (2002) LTRPC2 $\mathrm{Ca}^{2+}$-permeable channel activated by changes in redox status confers susceptibility to cell death. Mol Cell 9:163-173. CrossRef Medline

Haraguchi K, Kawamoto A, Isami K, Maeda S, Kusano A, Asakura K, Shirakawa H, Mori Y, Nakagawa T, Kaneko S (2012) TRPM2 contributes to inflammatory and neuropathic pain through the aggravation of pronociceptive inflammatory responses in mice. J Neurosci 32:3931-3941. CrossRef Medline

Hardingham GE (2006) Pro-survival signalling from the NMDA receptor. Biochem Soc Trans 34:936-938. CrossRef Medline

Hardingham GE, Bading H (2003) The Yin and Yang of NMDA receptor signalling. Trends Neurosci 26:81-89. CrossRef Medline

Hardingham GE, Bading H (2010) Synaptic versus extrasynaptic NMDA receptor signalling: implications for neurodegenerative disorders. Nat Rev Neurosci 11:682-696. CrossRef Medline

Hardingham GE, Arnold FJ, Bading H (2001) A calcium microdomain near NMDA receptors: on switch for ERK-dependent synapse-to-nucleus communication. Nat Neurosci 4:565-566. CrossRef Medline

Harteneck C, Frenzel H, Kraft R (2007) N-(p-amylcinnamoyl)anthranilic acid (ACA): a phospholipase A(2) inhibitor and TRP channel blocker. Cardiovasc Drug Rev 25:61-75. CrossRef Medline

Hetman M, Cavanaugh JE, Kimelman D, Xia Z (2000) Role of glycogen synthase kinase-3 beta in neuronal apoptosis induced by trophic withdrawal. J Neurosci 20:2567-2574. Medline

Ikonomidou C, Turski L (2002) Why did NMDA receptor antagonists fail 
clinical trials for stroke and traumatic brain injury? Lancet Neurol 1:383386. CrossRef Medline

Jia J, Verma S, Nakayama S, Quillinan N, Grafe MR, Hurn PD, Herson PS (2011) Sex differences in neuroprotection provided by inhibition of TRPM2 channels following experimental stroke. J Cereb Blood Flow Metab 31:2160-2168. CrossRef Medline

Jiang X, Tian F, Mearow K, Okagaki P, Lipsky RH, Marini AM (2005) The excitoprotective effect of $\mathrm{N}$-methyl-D-aspartate receptors is mediated by a brain-derived neurotrophic factor autocrine loop in cultured hippocampal neurons. J Neurochem 94:713-722. CrossRef Medline

Kamsler A, Segal M (2003) Hydrogen peroxide modulation of synaptic plasticity. J Neurosci 23:269-276. Medline

Kaneko S, Kawakami S, Hara Y, Wakamori M, Itoh E, Minami T, Takada Y, Kume T, Katsuki H, Mori Y, Akaike A (2006) A critical role of TRPM2 in neuronal cell death by hydrogen peroxide. J Pharmacol Sci 101:66-76. CrossRef Medline

Kraft R, Grimm C, Grosse K, Hoffmann A, Sauerbruch S, Kettenmann H, Schultz G, Harteneck C (2004) Hydrogen peroxide and ADP-ribose induce TRPM2-mediated calcium influx and cation currents in microglia. Am J Physiol Cell Physiol 286:C129-C137. CrossRef Medline

Lange I, Yamamoto S, Partida-Sanchez S, Mori Y, Fleig A, Penner R (2009) TRPM2 functions as a lysosomal $\mathrm{Ca}^{2+}$-release channel in beta cells. Sci Signal 2:1-11. CrossRef Medline

Lau A, Tymianski M (2010) Glutamate receptors, neurotoxicity and neurodegeneration. Pflugers Arch 460:525-542. CrossRef Medline

Lees KR, Asplund K, Carolei A, Davis SM, Diener HC, Kaste M, Orgogozo JM, Whitehead J (2000) Glycine antagonist (gavestinel) in neuroprotection (GAIN International) in patients with acute stroke: a randomised controlled trial. Lancet 355:1949-1954. CrossRef Medline

Li RW, Yu W, Christie S, Miralles CP, Bai J, Loturco JJ, De Blas AL (2005) Disruption of postsynaptic GABA receptor clusters leads to decreased GABAergic innervation of pyramidal neurons. J Neurochem 95:756-770. CrossRef Medline

Linseman DA, Butts BD, Precht TA, Phelps RA, Le SS, Laessig TA, Bouchard RJ, Florez-McClure ML, Heidenreich KA (2004) Glycogen synthase kinase-3 beta phosphorylates bax and promotes its mitochondrial localization during neuronal apoptosis. J Neurosci 24:9993-10002. CrossRef Medline

Liu L, Wong TP, Pozza MF, Lingenhoehl K, Wang Y, Sheng M, Auberson YP, Wang YT (2004) Role of NMDA receptor subtypes in governing the direction of hippocampal synaptic plasticity. Science 304:1021-1024. CrossRef Medline

Liu M, Hurn PD, Roselli CE, Alkayed NJ (2007) Role of P450 aromatase in sex-specific astrocytic cell death. J Cereb Blood Flow Metab 27:135-141. CrossRef Medline

Liu Y, Wong TP, Aarts M, Rooyakkers A, Liu L, Lai TW, Wu DC, Lu J, Tymianski M, Craig AM, Wang YT (2007) NMDA receptor subunits have differential roles in mediating excitotoxic neuronal death both in vitro and in vivo. J Neurosci 27:2846-2857. CrossRef Medline

Maalouf M, Rho JM (2008) Oxidative impairment of hippocampal long-term potentiation involves activation of protein phosphatase $2 \mathrm{~A}$ and is prevented by ketone bodies. J Neurosci Res 86:3322-3330. CrossRef Medline

Martel MA, Soriano FX, Baxter P, Rickman C, Duncan R, Wyllie DJ, Hardingham GE (2009) Inhibiting pro-death NMDA receptor signaling dependent on the NR2 PDZ ligand may not affect synaptic function or synaptic NMDA receptor signaling to gene expression. Channels 3:12-15. CrossRef Medline

Monyer H, Burnashev N, Laurie DJ, Sakmann B, Seeburg PH (1994) Developmental and regional expression in the rat brain and functional properties of four NMDA receptors. Neuron 12:529-540. CrossRef Medline

Nadler MJ, Hermosura MC, Inabe K, Perraud AL, Zhu Q, Stokes AJ, Kurosaki T, Kinet JP, Penner R, Scharenberg AM, Fleig A (2001) LTRPC7 is a Mg center dot ATP-regulated divalent cation channel required for cell viability. Nature 411:590-595. CrossRef Medline

Olah ME, Jackson MF, Li H, Perez Y, Sun HS, Kiyonaka S, Mori Y, Tymianski $\mathrm{M}$, MacDonald JF (2009) $\mathrm{Ca}^{2+}$-dependent induction of TRPM2 currents in hippocampal neurons. J Physiol 587:965-979. CrossRef Medline

Papadia S, Stevenson P, Hardingham NR, Bading H, Hardingham GE (2005)
Nuclear $\mathrm{Ca}^{2+}$ and the cAMP response element-binding protein family mediate a late phase of activity-dependent neuroprotection. J Neurosci 25:4279-4287. CrossRef Medline

Perraud AL, Takanishi CL, Shen B, Kang S, Smith MK, Schmitz C, Knowles HM, Ferraris D, Li W, Zhang J, Stoddard BL, Scharenberg AM (2005) Accumulation of free ADP-ribose from mitochondria mediates oxidative stress-induced gating of TRPM2 cation channels. J Biol Chem 280:61386148. CrossRef Medline

Sattler R, Charlton MP, Hafner M, Tymianski M (1997) Determination of the time-course and extent of neurotoxicity at defined temperatures in cultured neurons using a modified multi-well plate fluorescence scanner. J Cereb Blood Flow Metab 17:455-463. CrossRef Medline

Sattler R, Xiong ZG, Lu WY, Hafner M, MacDonald JF, Tymianski M (1999) Specific coupling of NMDA receptor activation to nitric oxide neurotoxicity by PSD-95 protein. Science 284:1845-1848. CrossRef Medline

Simonson SG, Zhang J, Canada AT Jr, Su YF, Benveniste H, Piantadosi CA (1993) Hydrogen peroxide production by monoamine oxidase during ischemia-reperfusion in the rat brain. J Cereb Blood Flow Metab 13:125134. CrossRef Medline

Soriano FX, Papadia S, Hofmann F, Hardingham NR, Bading H, Hardingham GE (2006) Preconditioning doses of NMDA promote neuroprotection by enhancing neuronal excitability. J Neurosci 26:4509-4518. CrossRef Medline

Soriano FX, Martel MA, Papadia S, Vaslin A, Baxter P, Rickman C, Forder J, Tymianski M, Duncan R, Aarts M, Clarke P, Wyllie DJ, Hardingham GE (2008) Specific targeting of pro-death NMDA receptor signals with differing reliance on the NR2B PDZ ligand. J Neurosci 28:10696-10710. CrossRef Medline

Stanika RI, Pivovarova NB, Brantner CA, Watts CA, Winters CA, Andrews SB (2009) Coupling diverse routes of calcium entry to mitochondrial dysfunction and glutamate excitotoxicity. Proc Natl Acad Sci U S A 106: 9854-9859. CrossRef Medline

Sun HS, Jackson MF, Martin LJ, Jansen K, Teves L, Cui H, Kiyonaka S, Mori Y, Jones M, Forder JP, Golde TE, Orser BA, Macdonald JF, Tymianski M (2009) Suppression of hippocampal TRPM7 protein prevents delayed neuronal death in brain ischemia. Nat Neurosci 12:1300-1307. CrossRef Medline

Terasaki Y, Sasaki T, Yagita Y, Okazaki S, Sugiyama Y, Oyama N, OmuraMatsuoka E, Sakoda S, Kitagawa K (2010) Activation of NR2A receptors induces ischemic tolerance through CREB signaling. J Cereb Blood Flow Metab 30:1441-1449. CrossRef Medline

Tymianski M (2011) Emerging mechanisms of disrupted cellular signaling in brain ischemia. Nat Neurosci 14:1369-1373. CrossRef Medline

Vereker E, O’Donnell E, Lynch A, Kelly A, Nolan Y, Lynch MA (2001) Evidence that interleukin- 1 beta and reactive oxygen species production play a pivotal role in stress-induced impairment of LTP in the rat dentate gyrus. Eur J Neurosci 14:1809-1819. CrossRef Medline

Wenzel A, Fritschy JM, Mohler H, Benke D (1997) NMDA receptor heterogeneity during postnatal development of the rat brain: differential expression of the NR2A, NR2B, and NR2C subunit proteins. J Neurochem 68:469-478. CrossRef Medline

Xie YF, Belrose JC, Lei G, Tymianski M, Mori Y, MacDonald JF, Jackson MF (2011) Dependence of NMDA/GSK-3 $\beta$ mediated metaplasticity on TRPM2 channels at hippocampal CA3-CA1 synapses. Mol Brain 4:44. CrossRef Medline

Yamamoto S, Shimizu S, Kiyonaka S, Takahashi N, Wajima T, Hara Y, Negoro T, Hiroi T, Kiuchi Y, Okada T, Kaneko S, Lange I, Fleig A, Penner R, Nishi M, Takeshima H, Mori Y (2008) TRPM2-mediated $\mathrm{Ca}^{2+}$ influx induces chemokine production in monocytes that aggravates inflammatory neutrophil infiltration. Nat Med 14:738-747. CrossRef Medline

Zawadzka M, Kaminska B (2003) Immunosuppressant FK506 affects multiple signaling pathways and modulates gene expression in astrocytes. Mol Cell Neurosci 22:202-209. CrossRef Medline

Zhou M, Baudry M (2006) Developmental changes in NMDA neurotoxicity reflect developmental changes in subunit composition of NMDA receptors. J Neurosci 26:2956-2963. CrossRef Medline 